\title{
Gene expression analysis of human prostate cell lines with and without tumor metastasis suppressor CD82
}

\author{
Pushpaja Dodla', Vanitha Bhoopalan ${ }^{1}$, Sok Kean Khoo ${ }^{1}$, Cindy Miranti ${ }^{2}$ and Suganthi Sridhar ${ }^{3^{*}}$ (D)
}

\begin{abstract}
Background: Tetraspanin CD82 is a tumor metastasis suppressor that is known to down regulate in various metastatic cancers. However, the exact mechanism by which CD82 prevents cancer metastasis is unclear. This study aims to identify genes that are regulated by CD82 in human prostate cell lines.

Methods: We used whole human genome microarray to obtain gene expression profiles in a normal prostate epithelial cell line that expressed CD82 (PrEC-31) and a metastatic prostate cell line that does not express CD82 (PC3). Then, siRNA silencing was used to knock down CD82 expression in PrEC-31 while CD82 was re-expressed in $P C 3$ to acquire differentially-expressed genes in the respective cell line.

Results: Differentially-expressed genes with a $P<0.05$ were identified in 3 data sets: PrEC-31 (+CD82) vs PrEC31 (-CD82), PC3-57 (+CD82) vs. PC3-5 V (-CD82), and PC3-29 (+CD82) vs. PC3-5 V (-CD82). Top 25 gene lists did not show overlap within the data sets, except (CALB1) the calcium binding protein calbindin 1 which was significantly up-regulated (2.8 log fold change) in PrEC-31 and PC3-29 cells that expressed CD82. Other most significantly up-regulated genes included serine peptidase inhibitor kazal type 1 (SPINK1) and polypeptide N-acetyl galactosaminyl transferase 14 (GALNT14) and most down-regulated genes included C-X-C motif chemokine ligand 14 (CXCL14), urotensin 2 (UTS2D), and fibroblast growth factor 13 (FGF13). Pathways related with cell proliferation and angiogenesis, migration and invasion, cell death, cell cycle, signal transduction, and metabolism were highly enriched in cells that lack CD82 expression. Expression of two mutually inclusive genes in top 100 gene lists of all data sets, runt-related transcription factor (RUNX3) and trefoil factor 3 (TFF3), could be validated with qRT-PCR.

Conclusion: Identification of genes and pathways regulated by CD82 in this study may provide additional insights into the role that CD82 plays in prostate tumor progression and metastasis, as well as identify potential targets for therapeutic intervention.
\end{abstract}

Keywords: CD82, KAl1, Metastasis tumor suppressor, Prostate cancer, Microarray, Gene expression

\footnotetext{
* Correspondence: suganthi@usf.edu

${ }^{3}$ Department of Integrative Biology, University of South Florida, 140, 7Th

Avenue S, University of South Florida, St. Petersburg, FL 33701, USA

Full list of author information is available at the end of the article
}

(c) The Author(s). 2020 Open Access This article is licensed under a Creative Commons Attribution 4.0 International License, which permits use, sharing, adaptation, distribution and reproduction in any medium or format, as long as you give appropriate credit to the original author(s) and the source, provide a link to the Creative Commons licence, and indicate if changes were made. The images or other third party material in this article are included in the article's Creative Commons licence, unless indicated otherwise in a credit line to the material. If material is not included in the article's Creative Commons licence and your intended use is not permitted by statutory regulation or exceeds the permitted use, you will need to obtain permission directly from the copyright holder. To view a copy of this licence, visit http://creativecommons.org/licenses/by/4.0/ The Creative Commons Public Domain Dedication waiver (http://creativecommons.org/publicdomain/zero/1.0/) applies to the data made available in this article, unless otherwise stated in a credit line to the data. 


\section{Background}

Metastasis, the spread of malignant cells from a primary tumor to surrounding tissues and distant organs involves complex cell signalling processes and regulators. Despite the ongoing research and therapeutic development, metastatic cancer remains incurable. The survival rates for metastatic cancers vary, but at large, are extremely low. If metastatic regulators and the cell signaling processes governing metastasis are identified and fully elucidated, they can be potential targets for oncologic treatment.

Prostate cancer is the second leading cause of cancer death in males in the United States. Metastatic prostate cancer has a five-year survival rate of $31 \%$. Although many genes involved in prostate tumor development have been identified, the exact role that they play in tumor progression or metastasis is unclear. CD82, a protein product of the KAI-1 or CD82 gene, was first identified as a metastasis tumor suppressor in rat prostate cells in 1995 [1]. Since then, CD82 expression levels have been reported to be negatively correlated to the metastatic potential in prostate tumors [2-4] and other epithelial tumors including gastric [5], colon $[6,7]$, cervix $[8,9]$, breast $[10,11]$, skin $[12]$, bladder $[13,14]$ lung [15], pancreas [16], liver [17-19], and thyroid [20]. CD82 currently serves as a diagnostic biomarker and its down-regulation is recognized widely as a predictor of metastatic potential in various solid malignant tumors [21].

CD82 is a member of the tetraspanins, which is a family of proteins with 4 transmembrane domains: one large and one small extracellular loop and two short cytoplasmic $\mathrm{N}$ - and C-domains; the large extracellular loop has at least two disulfide bonds [22, 23]. Tetraspanins play a major role in cell proliferation, adhesion, motility, signaling, and metastasis [21-24].. CD82 is known to associate with integral protein such as integrins $(\alpha 3 \beta 1, \alpha 4 \beta 1$, $\alpha 5 \beta 1, \alpha 6 \beta 1$, and $\alpha v \beta 2$ ), cell adhesion molecules (E-cadherin, EWI-2), growth factor receptors such as epidermal growth factor receptor (EGFR), other tetraspanins (CD9, CD81, CD151), and intracellular signaling molecules such as protein kinase C [25-28]. CD82 has been well documented as an inhibitor of cell motility, invasion, and survival in cancer cells [25-27], with varied inhibition mechanisms. For example, CD82 regulation involves EGFR, hepatocyte growth factor receptor (c-Met), and transforming growth factor beta (TGF- $\beta$ ) in breast, prostate, and kidney cancers, respectively [29-31]. In breast cancer cells, CD82 inhibits ligand-induced dimerization of EGFR, attenuating the downstream signalling pathways of mitogen-activated protein kinase (MAPK), signal transducer and activator of transcription protein (STAT), and mammalian target of rapamycin (mTOR) that leads to cell proliferation and survival [29, 32]. CD82 also regulates EGFR ubiquitylation by recruiting protein kinase $C$ and phosphorylating both EGFR and EGFR ubiquitin ligase E3
(Cbl) to promote internalization of EGFR [33, 34]. In metastatic prostate cell line $\mathrm{PC} 3$, restoration of CD82 suppressed integrin-mediated activation of c-Met, leading to decreased activation of a protooncogene tyrosine kinase (Src) and subsequent deactivation of several Src substrates, including breast cancer anti-estrogen resistance 1 Cas family member (p130Cas), focal adhesion kinase (FAK) [30], and p130Cas-Crk (an adapter protein) coupling and deactivation of CUB domain containing protein 1 (CDCP1) [35]. The exact mechanism by which CD82 inhibits Src is unclear, but it is not through inhibition of the receptor c-Met upstream [30]. c-Met inhibition by CD82 could involve mechanisms similar to those observed in breast cancer cells. A recent study suggests that CD82 may suppress epithelial to mesenchymal transition (EMT) in prostate cancer cells on fibronectin matrix by laterally interacting with $\alpha 3 \beta 1$ and $\alpha 5 \beta 1$ integrins to repress integrin signaling [36], inhibiting cell migration and invasion. In renal carcinoma cells, CD82 seems to play a prominent role in migration and invasion by blocking TGF- $\beta 1 / \mathrm{Smad}$ signaling pathway. When CD82 was overexpressed in these cells, the expression of both metalloproteinases MMP2 and MMP9 and TGF- $\beta 1$ protein, a regulator of MMPs, were significantly decreased. CD82 overexpression also affected the phosphorylation state of the transcription factors Smad2 and Smad3, the downstream signaling molecules to TGF- $\beta 1$ [31].

On the other hand, CD82's role as a positive regulator has been extensively studied in $\mathrm{T}$ cell signaling. CD82 promotes $\mathrm{T}$ cell receptor signaling by triggering actin polymerization and stabilizing the downstream signaling of the $\mathrm{T}$ cell receptor (TCR/CD3) [37, 38]. CD82 promotes changes in $\mathrm{T}$ cell morphology involving the Rho GTPase pathway (Rho A, Rac1, and Cdc42) and through association with the guanine nucleotide exchange factor Vav1 and the adapter molecule SLP76 [39]. When T cells interact with antigen-presenting cells, a dynamic re-localization of CD82 and F-actin was observed at the periphery of the immune synapse, suggesting CD82's role in membrane dynamics during $\mathrm{T}$-cell signaling [40]. CD82 has been shown to promote enhanced cell to cell adhesion through E-cadherin in epithelial cells, i.e., CD82 expression in prostate cancer cells promoted Ecadherin-induced adhesion strongly by stabilizing Ecadherin's association with $\beta$-catenin, a complex required for E-cadherin function and stability [41].

Studies on hematopoietic stem cells (HSC) have revealed CD82 positively regulates both in vivo and in vitro homing of HSC to the bone marrow for bone marrow engraftment $[42,43]$. When CD82 was knocked down in mice, CD82 null mice had reduced long-lived HSC in vivo, with a decreased affinity of the cells to the endosteum. In addition, CD82 null mice exhibited weaker and smaller bones along with a decreased number of osteoclasts, increased adipogenesis, and 
decreased bone formation rate overall. In vitro phenotypes exhibited increased adipocyte numbers, defective osteoclast polarization, and decreased osteoblast differentiation and mineralization, indicative of defects in osteoclast, osteoblast, and adipocyte lineages [44]. Furthermore, a conditional CD82 knockout study in osteoclasts revealed CD82 loss did not affect cortical bone, osteoblasts or adipocytes [45]. However, an increase in osteoclast function and defects in actin assembly with altered osteoclast morphology were observed. The expression of the integrin $\alpha v \beta 3$ was also reduced, while $\beta 1$ integrin levels were high, with signaling to Src, Syk, and Vav compromised. The expression levels of the pattern recognition receptor Clec2 and its ligand, podoplanin, which signal to Syk and Vav, were increased, all suggesting CD82's role in cytoskeleton assembly and its overall role for normal osteoclast function. In another study involving platelets in CD82 null mice [46], loss of CD82 resulted in reduced bleeding time in vivo. There was no difference in platelet activation, degranulation, or aggregation, but the kinetics of clot retraction was enhanced. There was increased surface expression of $\alpha \operatorname{IIb} \beta 3$ integrins, enhanced adhesion, and increased tyrosine kinase signaling on fibrinogen.

CD82 as a metastasis suppressor seems to associate and mediate several different proteins through regulation of a variety of signaling pathways. Since the loss of CD82 has been linked to many different cellular events, there is a high possibility that CD82 may be regulating more than one protein or one pathway in prostate cells, i.e., the presence or absence of CD82 in prostate cells may cause changes in gene expression profiles with the accompanying protein expression in these cells. Thus, studying these profiles and identifying the genes involved in these cells will help us better understand CD82's role as a tumor metastasis suppressor in prostate cancer. Previous gene expression studies include EST sequencing [47], serial analysis of gene expression [48], differential display PCR [49], and microarray [50]. Here, we use the whole human genome gene expression microarray to identify genes regulated by CD82 in normal prostate cells that express CD82 (PrEC-31) against the same cells subject to knocked down with CD82 siRNA. Conversely, metastatic prostate cell line PC3 that does not express CD82 were compared with its clones transfected with CD82. Quantitative realtime PCR (qRT-PCR) were then used to validate the microarray results [51, 52]. Identification of differentially expressed genes in these prostate cells will provide further information on the genes CD82 may regulate to help decipher an overall role for CD82 in metastasis prevention.

\section{Methods}

\section{Cell lines and cell culture}

Human normal prostate epithelial cells (PrEC-31) expressing CD82 were donated by Dr. Beatrice Knudsen, University of Utah, and were cultured as previously described [53]. Briefly, cells were maintained in keratinocyte serum-free medium supplemented with human recombinant EGF and bovine pituitary extract (Gibco) and kept at $37^{\circ} \mathrm{C}$ in a $5 \% \mathrm{CO}_{2}$ incubator. Cell authentication was tested with short tandem repeat (STR) analysis. Bone-derived metastatic prostate cell line PC3 was obtained from American Type Culture Collection (ATCC). Clones of PC3: PC3-5 V (empty vector transfected; -CD82), PC3-29 and PC3-57 (transfected with pCDNA3,1(PAL)N-flag.CD82 plasmid construct to express $\mathrm{CD} 82$ ), were generated as previously described [30]. All PC3 cells were maintained in F12K medium (Invitrogen), supplemented with 10\% fetal bovine serum, $2 \mathrm{mM}$ glutamine, and 50 units of penicillin and $50 \mu \mathrm{g}$ of streptomycin $/ \mathrm{ml}$, as previously described. When all cell cultures reached $70-80 \%$ confluence, they were trypsinized, pelleted, and stored at $-80^{\circ} \mathrm{C}$ for RNA extraction. Cell lysates were also collected to perform western blot.

\section{siRNA silencing of PrEC-31}

When PrEC-31 cells reached $70-80 \%$ confluency, they were split equally into a 6-well plate to determine the optimal CD82 siRNA concentration required for silencing CD82 expression. CD82 siRNA (5' GAGCAGTT TCATCTCTGTC 3') (Integrated DNA Technologies), in conjunction with siLentFect lipid reagent (Bio-Rad) was used to knock down CD82 from the PrEC-31 cells. siRNA silencing was optimized using various concentrations of siRNA ( $30 \mathrm{nM}, 40 \mathrm{nM}, 50 \mathrm{nM}$ and $60 \mathrm{nM}$ ), with $5 \mu \mathrm{L}$ of siLentFect lipid reagent for $48 \mathrm{~h}$. according to the manufacturer's instructions. Upon visualization of CD82 knockdown with Western blot described below, $40 \mathrm{nM}$ of CD82 siRNA concentration was selected as the optimal concentration for CD82 mass silencing. Thus, PrEC-31 cells were cultured in $10 \mathrm{~cm}$ plates and mass silencing was performed with $40 \mathrm{nM}$ siRNA with $5 \mu \mathrm{L}$ of siLentfect lipid reagent for $48 \mathrm{~h}$. PrEC-31 cells were also transfected with $40 \mathrm{nM}$ scrambled siRNA as controls. After $48 \mathrm{~h}$. of incubation, the cells were trypsinized, pelleted, and stored at $-80^{\circ} \mathrm{C}$ for RNA extraction. CD82 knockdown in CD82 siRNA and control cells was confirmed with western blot as described below.

\section{Western blot}

After the appropriate silencing period, the media was removed from the cells and washed with 1X PBS. Cells were lysed with MAP kinase lysis buffer [54] containing protease inhibitor cocktail. Fifty microliter of MAPK lysis buffer was added to the 6-well plates or $200 \mu$ of MAPK lysis buffer was added to the $10 \mathrm{~cm}$ plates and left on ice for $30 \mathrm{~min}$. The supernatant from the lysed cells was separated by centrifugation at $12,000 \mathrm{rpm}$ at $4{ }^{\circ} \mathrm{C}$ for $10 \mathrm{~min}$. The protein concentrations in the cell lysates were determined using Bicinchoninic Acid (Pierce 
Chemical Company) and subject to gel electrophoresis. Equal amounts of the protein samples were loaded onto a $10 \%$ precast Tris-Glycine gel (Novex) along with Pierce 3Color protein molecular weight marker mix (Thermo Scientific), ran at $125 \mathrm{~V}$ for $90 \mathrm{~min}$ and the blot transferred to a Polyvinylidene Fluoride (PVDF) membrane. The blot was subject to western blot analysis using CD82 (TS82b) antibodies (Abcam). Protein bands on the blot were visualized using SupersignalWest Pico chemiluminescent reagent (Thermo Scientific) per the manufacturer's instructions and images were captured using an UVP EpiChemi3 Darkroom UV transilluminator, attached to a Hamamatsu camera.

\section{Trizol precipitation and RNA isolation}

The cells were trypsinized and centrifuged at $1000 \mathrm{rpm}$ for 5 min before washing with $1 \mathrm{X}$ PBS to collect the cell pellet. Trizol precipitation and RNA isolation were then performed as previously described [55]. To remove genomic DNA contamination, a mixture of $3.5 \mu \mathrm{L}$ DNase buffer, $2 \mu \mathrm{L}$ RNAse inhibitor, and $2 \mu \mathrm{L}$ DNase I was added to the RNA followed by a 20 min incubation in a heat block at $37^{\circ} \mathrm{C}$. Total RNA was isolated and purified using RNeasy Mini Kit (Qiagen) according to the manufacturer's instructions. The RNA was then quantified using a NanoVue spectrophotometer (General Electric).

\section{Gene expression microarray assay}

Metastatic prostate cells (PC3-5 V, PC3-29, and PC357), normal prostate cells PrEC-31 (+CD82), and PrEC31 treated with scrambled siRNA (-CD82) were used to perform gene expression microarray assay. The $4 \times 44 \mathrm{~K}$ whole human genome two-color microarray (Agilent) was used with quick amp labeling protocol. First, RNA was spiked with Spike A and Spike B mixes for cyanin-3 (cy-3, green) and cyanin-5 (cy-5, red) dyes, respectively. The RNA was then reverse transcribed to the first and second strand of cDNA. cRNA was transcribed from the second-strand of cDNA and labelled with either cy-3 or cy-5. Labeled cRNA were cleaned up using Rneasy mini spin column kit (Qiagen) before quantification with a NanoDrop. cRNA were then fragmented for $30 \mathrm{~min}$ with fragmentation buffer before hybridization overnight in the microarray slide at $65^{\circ} \mathrm{C}$. The microarray array slide was then washed with wash buffers 1 and 2 and was scanned using a microarray scanner (Agilent). Microarray probe featured information was extracted using Agilent Feature Extraction Software according to manufacturer's instructions. The results were stored as raw data files in excel sheets.

\section{Microarray data analysis}

Data Analysis was performed on three sets of microarray raw data, comparing $\mathrm{PC} 3-29(+\mathrm{CD} 82)$ vs. PC3-5 V
(-CD82), PC3-57 (+CD82) vs. PC3-5 V (-CD82), and PrEC-31 (+CD82) vs. PrEC-31 knocked down with CD82 siRNA (-CD82), using Bioconductor $\mathrm{R}$, a statistical programming environment. First, the library was loaded, and the target files were imported into the $R$ workspace. The required fields such as gProcessedSignal, rProcessedSignal, gProcessedSigError, rProcessedSigError were read from the target files using the "read.maimages" command. A matrix was created for both red and green process signals using the "matrix" command. The data was then subjected to background correction and then normalization with loess method using the "normalizeWithinArrays" command. Normalized data was then filtered for positive and negative controls and duplicate probe values were aggregated using the "aggregate" command. Agilent probe names were then annotated with Entrez gene names and gene symbols. Commands for MA plots were then executed for a visual comparison of raw and normalized data for all three comparisons. Statistical analysis of the data was performed before which a model matrix was created where control and treatments were specified $(-\mathrm{CD} 82$ vs. + CD82). Linear model analysis was performed in Limma using Bayes fit method where t-test was performed between the control and treatment. The top differentially expressed genes with $P<0.05$ were listed after adjusting with false discovery rate method. Heat maps for the top 25 genes were generated using $\mathrm{R}$ programming. Parametric gene set enrichment analysis (PGSEA) library was loaded and Smc (significant multivariate correlation) plots were drawn by specifying the window dimensions.

\section{Pathway analysis}

Pathway analysis was performed for all statistical significantly expressed genes using the EASE software version 2.0 [56]. Briefly, gene symbols for each top 100 differentially expressed gene list were pasted and then to "Find Over-represented Gene category" was selected. Next, the list of all $44 \mathrm{~K}$ gene symbols that were present on the microarray slide was pasted and the analysis was run.

\section{qRT-PCR primer design and efficiency test}

qRT-PCR was performed on all 5 cell lines (PrEC-31 +/-CD82, PC3-5 V, PC3-57, and PC3-29), to validate the microarray results. Two significantly differentially expressed genes: RUNX family transcription factor 3 (RUNX3) and trefoil factor 3 (TFF3) that were common among all 3 data sets and were upregulated in + CD82 cell lines (PrEC-31 + CD82, PC3-57, and PC3-29) compared to -CD82 cell lines (PrEC-31 -CD82 and PC3-5 V) and with a $\operatorname{LogFC}$ value of 1.4 or above required for qRT-PCR validation [57] were selected. Primers for these genes and a normalizer gene ( $\beta$-actin) were designed using NCBI Primer Blast tool and Biology Workbench. 
Table 1 qRT-PCR primers for validating microarray gene expression

\begin{tabular}{|c|c|c|c|c|}
\hline & Primer orientation & Primer sequence $\left(5^{\prime}-3^{\prime}\right)$ & $\begin{array}{l}\text { Melting Temperature } \\
\left(\mathrm{Tm}^{\circ} \mathrm{C}\right)\end{array}$ & GC\% \\
\hline \multirow[t]{2}{*}{ RUNX3 } & Forward primer & GACAGCCCCAACTTCCTCT & 56.9 & 57.8 \\
\hline & Reverse primer & CACAGTCACCACCGTACCAT & 57.0 & 55 \\
\hline \multirow[t]{2}{*}{ TFF3 } & Forward primer & TCAAGCCCCTGCAGGAAGCAG & 62.4 & 61.9 \\
\hline & Reverse primer & GCCGGGAGCAAAGGGACAGA & 62.4 & 65 \\
\hline \multirow[t]{2}{*}{$\beta$-actin } & Forward primer & AGCACTGTGTTGGCGTACAG & 57.9 & 55 \\
\hline & Reverse primer & СTCTTCCAGCCTTCCTTCCT & 56.4 & 55 \\
\hline
\end{tabular}

All primers were designed to span at least one exon-exon junction. These primers were tested for the presence of primer dimers and hairpins using Lasergene Primer Select tool. Primer sequences that had the least number of dimers and hairpins were selected and custom made by Integrated DNA Technologies. Lyophilized forward and reverse primers were reconstituted in sterile distilled water and diluted to $5 \mu \mathrm{M}$ for qRT-PCR assays. For primer efficiency test, $2 \mu \mathrm{g}$ of RNA from either PC3-5 V, PC3-29, or
PC3-57 was converted to cDNA using cDNA reverse transcriptase kit (Applied Biosystems) with the manufacturer's instructions and RNase inhibitor. $150 \mathrm{nM}$ final concentration of each primer (forward and reverse) with serially diluted cDNA $(1: 25,1: 100,1: 400)$ was amplified with Brilliant II SYBR green qPCR master mix kit (Stratagene) and fluorescent intensity detected in a MX3000P qPCR machine (Stratagene). For each gene, those without cDNA template were assigned as negative controls and all

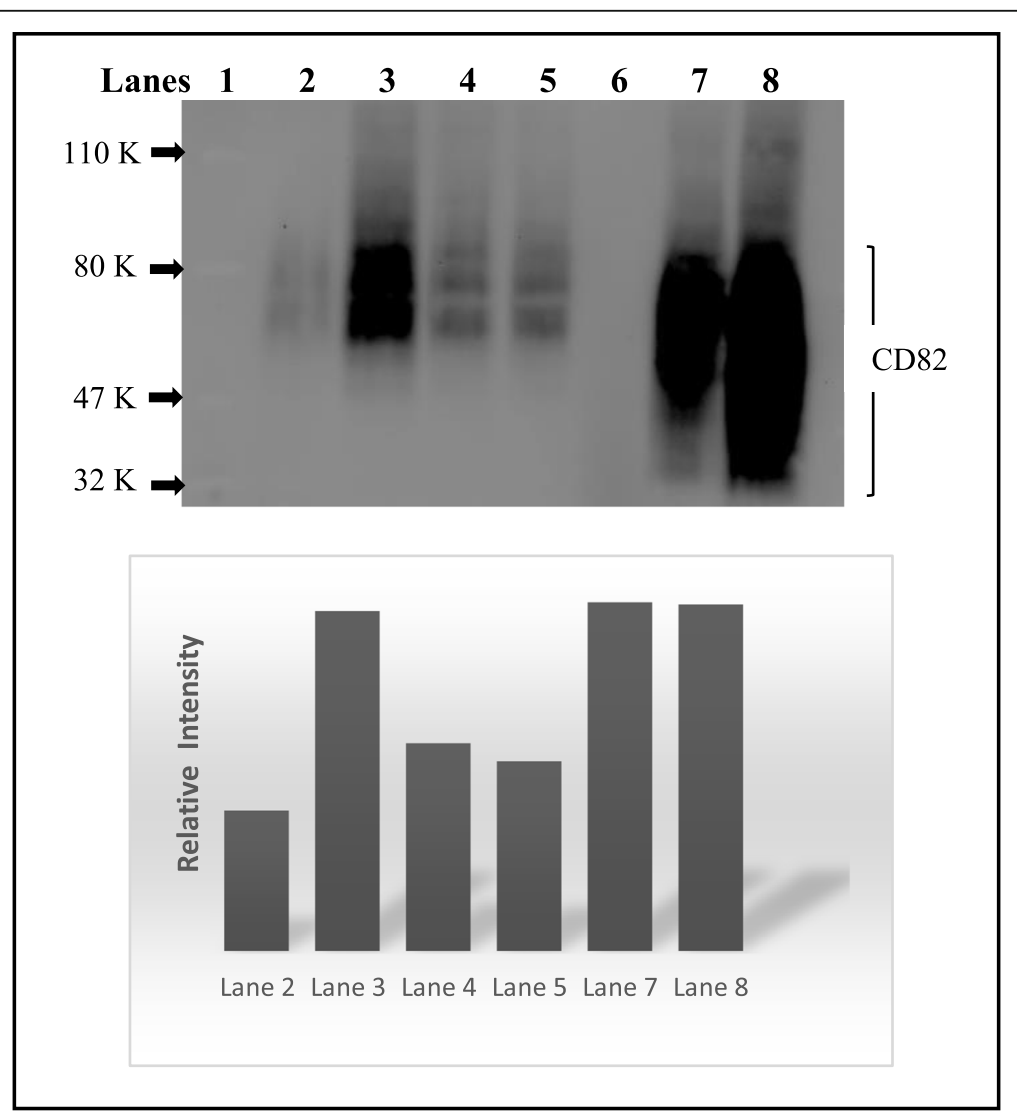

Fig. 1 Western blot of CD82 protein expression in prostate cancer cell lines. Lane 1. Protein ladder with Phosphorylase B (110 K), BSA (80 K), Ovalbumin (47 K), and Carbonic Anhydrase (32 K). Lane 2. PC3-5 V metastatic prostate clonal cells with empty vector, Lane 3. PrEC-31 transfected with $40 \mathrm{nM}$ of scrambled siRNA. Lane 4 and 5. PrEC-31 transfected with $30 \mathrm{nM}$ and $40 \mathrm{nM}$ of CD82 siRNA, respectively. Lane 6. empty. Lane 7 and 8. PC3-29 and PC3-57 clonal cells. Restored with CD82, respectively. A heavily glycosylated CD82 runs as a wide band between 30 and 90 KDa. Below is a graph that represents the relative intensity of the CD82 band in different lanes, based on the densitometric analysis of the blot. An uncropped full-length blot is presented in supplementary Fig. S9 
reactions were performed in triplicate. Reference dye was used for all efficiency tests with both SYBR and ROX dyes examined. The concentration of each sample was known to calculate the efficiency using a standard curve. All thermal profile settings were left as default except annealing temperature raised to $60^{\circ} \mathrm{C}$ and the dissociation curve cycles were selected. Amplification plots, dissociation curves, and standard curves were then analyzed using threshold cycle $(\mathrm{Ct})$ values and primers with the highest efficiency were used for comparative quantification of the genes (Table 1).

\section{Validating microarray results with qRT-PCR}

The gene expression levels of RUNX3 and TFF3 in all cell lines was examined. $\beta$-actin was used as the normalizer gene and 1:10 dilutions of cDNA were used. Gene expression in PC3-57 and PC3-29 cells (+CD82) was assessed with PC3-5 V cells (-CD82) as a calibrator, while the PrEC-31 knocked down cells with CD82 siRNA (-CD82) was the calibrator for the normal prostate
PrEC-31 (+CD82) cells. All samples were run in triplicate and reference dye ROX was used. qRT-PCR was performed as described above. Threshold cycle values were obtained to assess the gene expression. Student t-tests were performed to compare the gene expression and $p$ values less than 0.05 were regarded as statistically significant.

\section{Results \\ CD82 siRNA silencing in normal prostate cells and restoration in metastatic cells}

We showed that CD82 can be silenced or restored in prostate cell lines (Fig. 1). Treatment with CD82 siRNA generated close to $50 \%$ knockout of CD82 expression in normal prostate cells (lanes 4 and 5) compared to treatment with scrambled siRNA (lane 3). The siRNA knockdown was close to comparison to CD82 expression in metastatic prostate PC3 cells without CD82 (clone PC3-5 $\mathrm{V}$, lane 2). PC3 clones with CD82 reexpressed (PC3-29 and $\mathrm{PC} 3-57$, lane 7 and 8 , respectively) showed restoration

Table 2 List of top 25 differentially expressed genes between PrEC (+CD82) vs. PrEC (-CD82) cells

\begin{tabular}{|c|c|c|c|c|c|}
\hline Gene Name & Gene ID & Gene Description & $\log \mathrm{FC}$ & t-value & $p$-value \\
\hline SPINK1 & NM_003122 & Homo sapiens serine peptidase inhibitor, Kazal type 1 & 4.049 & 20.68 & $2.91 \mathrm{E}-08$ \\
\hline FAM115C & NM_001130025.1 & Homo sapiens family with sequence similarity 115 , member $C$ & 3.492 & 13.18 & $9.91 \mathrm{E}-07$ \\
\hline KRTAP19-1 & NM_181607 & Homo sapiens keratin associated protein 19-1 & 3.488 & 21.92 & 1.83E-08 \\
\hline KRT80 & NM_182507 & Homo sapiens keratin 80 & 3.372 & 19.55 & 4.53E-08 \\
\hline GPRC5A & NM_003979 & Homo sapiens $G$ protein-coupled receptor, familyC, group 5, member A & 3.352 & 17.86 & $9.26 \mathrm{E}-08$ \\
\hline ANGPTL4 & NM_139314 & Homo sapiens angiopoietin-like 4, transcript variant 1 & 3.243 & 18.89 & 5.96E-08 \\
\hline CEACAM6 & NM_002483 & Homo sapiens carcinoembryonic antigen-related cell adhesion molecule 6 & 3.166 & 17.55 & $1.06 \mathrm{E}-07$ \\
\hline SPC25 & NM_020675.3 & Homo sapiens NDC80 kinetochore complex component, homolog (S. cerevisiae) & 3.156 & 19.26 & $5.10 \mathrm{E}-08$ \\
\hline RNF183 & NM_145051 & Homo sapiens ring finger protein 183 & 3.058 & 13.93 & $6.45 \mathrm{E}-07$ \\
\hline HAS2 & NM_005328 & Homo sapiens hyaluronan synthase 2 & 3.009 & 18.95 & $5.81 \mathrm{E}-08$ \\
\hline NLRP3 & NM_001079821 & Homo sapiens NLR family, pyrin domain containing 3 & 2.999 & 16.22 & 1.97E-07 \\
\hline$C A L B 1$ & NM_004929 & Homo sapiens calbindin 1, $28 \mathrm{kDa}$ & 2.879 & 10.61 & $5.20 \mathrm{E}-06$ \\
\hline MT1JP & AF348994 & Homo sapiens metallothionein $1 \mathrm{~J}$ (pseudogene) & 2.796 & 17.52 & $1.08 \mathrm{E}-07$ \\
\hline S100P & NM_005980 & Homo sapiens S100 calcium binding protein P & 2.786 & 17.39 & $1.14 \mathrm{E}-07$ \\
\hline hCG_1749898 & NM_001165252.1 & Homo sapiens keratin associated protein 2-4-like & 2.769 & 17.41 & 1.13E-07 \\
\hline AKAP12 & NM_144497 & Homo sapiens A kinase (PRKA) anchor protein (gravin) 12, transcript variant 2 & 2.677 & 16.86 & $1.45 \mathrm{E}-07$ \\
\hline ILIR2 & NM_004633 & Homo sapiens interleukin 1 receptor, type II, transcript variant 1 & 2.657 & 10.31 & $6.47 \mathrm{E}-06$ \\
\hline FOXA2 & NM_021784.4 & Homo sapiens forkhead box A2 & -2.521 & -13.47 & $8.40 \mathrm{E}-07$ \\
\hline SLC24A3 & NM_020689.3 & $\begin{array}{l}\text { Homo sapiens solute carrier family } 24 \text { (sodium/potassium/calcium exchanger), } \\
\text { member } 3\end{array}$ & -2.591 & -15.84 & $2.38 \mathrm{E}-07$ \\
\hline KIAA1199 & NM_018689 & Homo sapiens KIAA1199 & -2.830 & -15.95 & $2.25 \mathrm{E}-07$ \\
\hline DNAJC12 & NM_021800 & Homo sapiens DNAJ (Hsp40) homolog, subfamily C, member 12, transcript variant 1 & -3.081 & -19.29 & $5.04 \mathrm{E}-08$ \\
\hline CDKN1C & NM_000076 & Homo sapiens cyclin-dependent kinase inhibitor $1 \mathrm{C}$ & -3.227 & -20.16 & $3.56 \mathrm{E}-08$ \\
\hline MIAT & NR_003491.2 & Homo sapiens myocardial infarction associated transcript (non-protein coding) & -3.241 & -20.21 & $3.50 \mathrm{E}-08$ \\
\hline POSTN & NM_006475 & Homo sapiens periostin, osteoblast specific factor & -3.408 & -14.07 & $5.98 \mathrm{E}-07$ \\
\hline CXCL14 & NM_004887 & Homo sapiens chemokine (C-X-C motif) ligand 14 & -3.774 & -19.93 & $3.89 \mathrm{E}-08$ \\
\hline
\end{tabular}


of CD82 with expression levels similar or higher than normal prostate cells PrEC-31 that expressed CD82 (lane 3). An uncropped gel blot is presented in supplementary Fig. S9.

\section{Microarray data normalization}

The first preprocessing step for microarray data is the log transformation of signal intensity ratios. However, dye labeling, especially in 2-color microarray, can create nonlinear bias in the log ratios and compromise raw microarray data. Thus, microarray raw data need to be normalized before analysis. A MA plot enables visualization between intensity and difference between 2 data stores for each microarray probe. MA plots generated from raw data vs. normalized data for each 2-color microarray used in this study were compared to show successful normalization process (Supplemental Fig. S1S3). The normalized data were then used to obtain the list of differentially expressed genes.

\section{Gene expression profiles of + CD82 and -CD82 prostate cells}

Gene expression level in cells expressing CD82 vs. those that do not express CD82 was compared with t-test and $\mathrm{t}$-values were generated. Differentially expressed genes with $P<0.05$ were identified and top 25 differentially expressed gene for PrEC-31 (+CD82) vs. PrEC-31 (-CD82), PC3-57 (+CD82) vs. PC3-5 V (-CD82), and PC3-29 (+CD82) vs. PC3-5 V (-CD82) (Table 2, 3, 4) were used to generate their respective gene expression profiles in heatmaps (Figs. 2, 3, 4).

Top 25 gene lists did not show overlap genes between the three arrays except calbindin 1 (CALB1) which was significantly upregulated $(2.8$ log-fold change or logFC) in PrEC-31 (+CD82) and PC3-29 $(+\mathrm{CD} 82)$ cells. In PrEC-31 (+CD82) vs. PrEC-31 (-CD82) cells, the most up- and down-regulated genes were serine peptidase inhibitor kazal type 1 (SPINK1; $4 \operatorname{logFC}$ ) and $\mathrm{C}-\mathrm{X}-\mathrm{C}$ motif chemokine ligand 14 (CXCL14;

Table 3 List of the top 25 differentially expressed genes between PC3-57 (+CD82) vs. PC3-5 V (-CD82) cell lines

\begin{tabular}{|c|c|c|c|c|c|}
\hline Gene Name & Gene ID & Gene Description & $\log \mathrm{FC}$ & t-value & $p$-value \\
\hline GALNT14 & NM_024572 & $\begin{array}{l}\text { Homo sapiens UDP-N-acetyl-alpha-D-galactosamine:polypeptide } \\
\mathrm{N} \text {-acetylgalactosaminyltransferase } 14\end{array}$ & 4.836 & 28.08 & $1.18 \mathrm{E}-09$ \\
\hline LRRC38 & CR622769 & Homo sapiens leucine rich repeat containing 38 & 4.452 & 25.60 & 2.56E-09 \\
\hline MTIM & NM_176870 & Homo sapiens metallothionein $1 \mathrm{M}$ & 4.064 & 20.80 & 1.45E-08 \\
\hline MAGEA2B & NM_153488 & Homo sapiens melanoma antigen family A, 2B & 4.003 & 16.87 & $8.22 \mathrm{E}-08$ \\
\hline MAGEA6 & NM_175868 & Homo sapiens melanoma antigen family A, 6, transcript variant 2 & 3.881 & 24.87 & 3.27E-09 \\
\hline HMOX1 & NM_002133 & Homo sapiens heme oxygenase (decycling) 1 & 3.851 & 23.67 & 4.94E-09 \\
\hline PRTFDC1 & NM_020200 & Homo sapiens phosphoribosyl transferase domain containing 1 & 3.845 & 21.87 & 9.55E-09 \\
\hline UTS2D & AK090630 & Homo sapiens urotensin 2 domain containing & -5.428 & -18.38 & 4.06E-08 \\
\hline KLF9 & NM_001206 & Homo sapiens Kruppel-like factor 9. & -5.01 & -32.08 & $3.86 \mathrm{E}-10$ \\
\hline$|F| 6$ & NM_022873 & Homo sapiens interferon, alpha-inducible protein 6, transcript variant 3 & -5.002 & -20.81 & 1.44E-08 \\
\hline RSAD2 & NM_080657 & Homo sapiens radical S-adenosyl methionine domain containing 2 & -4.812 & -28.08 & 1.18E-09 \\
\hline IFI44L & NM_006820 & Homo sapiens interferon-induced protein 44 -like & -4.803 & -30.10 & $6.60 \mathrm{E}-10$ \\
\hline$|F| H \mid$ & NM_022168 & Homo sapiens interferon induced with helicase $\mathrm{C}$ domain 1 & -4.775 & -30.06 & $5.78 \mathrm{E}-10$ \\
\hline MX2 & NM_002463 & Homo sapiens myxovirus (influenza virus) resistance 2 (mouse) & -4.572 & -28.68 & 9.89E-10 \\
\hline$A R H G D I B$ & NM_001175 & Homo sapiens Rho GDP dissociation inhibitor (GDI) beta & -4.568 & -25.62 & 2.55E-09 \\
\hline OAS2 & NM_016817 & Homo sapiens 2'-5'-oligoadenylate synthetase 2, transcript variant 1 & -4.445 & -24.84 & 3.30E-09 \\
\hline BST2 & NM_004335 & Homo sapiens bone marrow stromal cell antigen 2 & -4.338 & -16.78 & $8.61 \mathrm{E}-08$ \\
\hline SAMD9L & NM_152703 & Homo sapiens sterile alpha motif domain containing 9-like & -4.309 & -27.31 & 1.49E-09 \\
\hline CENPVL1 & NR_033772 & Homo sapiens centromere protein V-like 1 & -4.294 & -23.49 & 5.24E-09 \\
\hline MX1 & NM_002462 & $\begin{array}{l}\text { Homo sapiens myxovirus (influenza virus) resistance 1, } \\
\text { interferon-inducible protein p78 (mouse) }\end{array}$ & -4.147 & -24.49 & $3.71 \mathrm{E}-09$ \\
\hline HERC6 & NM_017912 & Homo sapiens hect domain and RLD 6 & -4.059 & -21.98 & 9.15E-09 \\
\hline IDO1 & NM_002164.4 & Homo sapiens indoleamine 2,3-dioxygenase 1 & -4.029 & -14.25 & 3.29E-07 \\
\hline HIST1H2BK & NM_080593 & Homo sapiens histone cluster 1, H2bk & -3.983 & -25.10 & 3.02E-09 \\
\hline IFIT1 & NM_001548 & Homo sapiens interferon-induced protein with tetratricopeptide repeats 1 & -3.914 & -20.17 & 1.87E-08 \\
\hline CNTNAP2 & NM_014141 & Homo sapiens contactin associated protein-like 2 & -3.886 & -19.95 & 2.05E-08 \\
\hline
\end{tabular}


Table 4 List of top 25 differentially expressed genes between PC3-29 (+CD82) vs. PC3-5 V (-CD82) cells

\begin{tabular}{|c|c|c|c|c|c|}
\hline Gene Name & Gene ID & Gene Description & $\log \mathrm{FC}$ & t-value & $p$-value \\
\hline CALB1 & NM_004929 & Homo sapiens calbindin 1, 28 kDa & 2.759 & 10.18 & $2.56 \mathrm{E}-24$ \\
\hline PELI2 & NM_021255 & Homo sapiens pellino homolog 2 & 2.246 & 8.28 & $1.22 \mathrm{E}-16$ \\
\hline DEFB103A & NM_018661 & Homo sapiens defensin, beta 103A & 2.216 & 8.17 & $3.14 \mathrm{E}-16$ \\
\hline TNS4 & NM_032865 & Homo sapiens tensin 4 & 2.212 & 8.16 & $3.48 \mathrm{E}-16$ \\
\hline SRPX & NM_006307.4 & Homo sapiens sushi-repeat-containing protein, $\mathrm{X}$-linked & -2.198 & -8.10 & $5.30 \mathrm{E}-16$ \\
\hline FGF13 & NM_004114 & Homo sapiens fibroblast growth factor 13 , transcript variant $1 \mathrm{~A}$ & -3.955 & -14.58 & $3.68 \mathrm{E}-48$ \\
\hline DNAH7 & NM_018897 & Homo sapiens dynein, axonemal, heavy chain 7 & -3.552 & -13.09 & $3.55 \mathrm{E}-39$ \\
\hline C9orf24 & NM_032596 & Homo sapiens chromosome 9 open reading frame 24, transcript variant 1 & -3.504 & -12.91 & $3.63 \mathrm{E}-38$ \\
\hline UTS2 & NM_021995 & Homo sapiens urotensin 2, transcript variant 1 & -3.436 & -12.66 & $8.93 \mathrm{E}-37$ \\
\hline HAPLN1 & NM_001884 & Homo sapiens hyaluronan and proteoglycan link protein 1 & -3.351 & -12.35 & $4.72 \mathrm{E}-35$ \\
\hline CXCR4 & NM_001008540 & Homo sapiens chemokine (C-X-C motif) receptor 4, transcript variant 1 & -3.303 & -12.17 & 4.14E-34 \\
\hline COL10A1 & NM_000493 & Homo sapiens collagen, type $X$, alpha 1 & -3.270 & -12.06 & $1.8 \mathrm{E}-33$ \\
\hline ANXA10 & NM_007193 & Homo sapiens annexin A10 & -3.014 & -11.11 & $1.09 \mathrm{E}-28$ \\
\hline NAP1L2 & NM_021963 & Homo sapiens nucleosome assembly protein 1 -like 2 & -2.987 & -11.01 & $3.32 \mathrm{E}-28$ \\
\hline BTG3 & NM_006806 & Homo sapiens BTG family, member 3 & -2.941 & -10.84 & 2.16E-27 \\
\hline GNG2 & NM_053064 & Homo sapiens guanine nucleotide binding protein (G protein), gamma 2 & -2.689 & -9.92 & $3.54 \mathrm{E}-23$ \\
\hline KRT37 & NM_003770 & Homo sapiens keratin 37 & -2.517 & -9.28 & $1.70 \mathrm{E}-20$ \\
\hline ILIB & NM_000576 & Homo sapiens interleukin 1, beta & -2.493 & -9.19 & 3.89E-20 \\
\hline IF/16 & NM_005531 & Homo sapiens interferon, gamma-inducible protein 16 & -2.439 & -8.99 & 2.42E-19 \\
\hline AKR1C1 & NM_001353 & $\begin{array}{l}\text { Homo sapiens aldo-keto reductase family 1, member C1 (dihydrodiol } \\
\text { dehydrogenase } 1 ; 20 \text {-alpha (3-alpha)-hydroxysteroid dehydrogenase) }\end{array}$ & -2.418 & -8.91 & 4.96E-19 \\
\hline SMARCA1 & NM_003069 & $\begin{array}{l}\text { Homo sapiens SWI/SNF related, matrix associated, actin dependent } \\
\text { regulator of chromatin, subfamily a, member } 1 \text {, transcript variant } 1\end{array}$ & -2.341 & -8.63 & $6.14 \mathrm{E}-18$ \\
\hline GNG11 & NM_004126 & Homo sapiens guanine nucleotide binding protein (G protein), gamma 11 & -2.309 & -8.51 & $1.69 \mathrm{E}-17$ \\
\hline BNIP3 & NM_004052 & Homo sapiens BCL2/adenovirus E1B 19 kDa interacting protein 3 & -2.296 & -8.46 & $2.59 \mathrm{E}-17$ \\
\hline MAP $1 B$ & NM_005909 & Homo sapiens microtubule-associated protein 1B, transcript variant 1 & -2.293 & -8.45 & $2.82 \mathrm{E}-17$ \\
\hline MLLT11 & NM_006818 & $\begin{array}{l}\text { Homo sapiens myeloid/lymphoid or mixed lineage leukemia } \\
\text { (trithorax homolog, Drosophila); translocated to, } 11\end{array}$ & -2.290 & -8.44 & 3.07E-17 \\
\hline
\end{tabular}

- $3.8 \log$ FC) respectively. The most upregulated gene was polypeptide $\mathrm{N}$-acetylgalactosaminyltransferase 14 (GALNT14; $4.8 \operatorname{logFC}$ ) in PC3-57 and calbindin 1 (CALB1; $2.8 \operatorname{logFC})$ in PC3-29 while the most downregulated gene was urotensin 2 (UTS2D; - 5.4 $\operatorname{logFC}$ ) in PC3-57 and fibroblast growth factor 13 (FGF13; $4 \operatorname{logFC}$ ) in $\mathrm{PC} 3-29$, when compared with $\mathrm{PC} 3-5 \mathrm{~V}$ cells.

\section{Pathway analysis}

Pathway analysis was performed to further explain the complex mechanisms of CD82 in the prostate cell lines. Top 100 significantly differentially expressed genes that were mutually inclusive in all 3 data sets-PC3-29 (+CD82), vs. PC3-5 V (-CD82), PC3-57 (+CD82) vs. PC3-5 V (-CD82), and PrEC-31 (+CD82) vs. PrEC-31 knocked down with CD82 siRNA (-CD82) were analyzed. The data showed that pathways related with cell proliferation and angiogenesis, migration and invasion, cell death, cell cycle, signal transduction, and metabolism were highly enriched (Table 5).

\section{qRT-PCR primer efficiency}

Dissociation curve, amplification plot, and standard curve of qRT-PCR were analyzed for primer efficiency of RUNX3 and TFF3 (Supplemental Fig. S4-S8). Dissociation curve analysis showed accurate amplification of each qRT-PCR target (Fig. S4), while amplification plot analysis showed appropriate fluorescence intensity range and exponential amplification (Fig. S5 and S7). Standard curve generated from $\mathrm{Ct}$ values in the amplification plot of known target quantity showed primers efficient between 86 to $99.9 \%(\mathrm{R} 2=0.998)$ (Fig. S6 and S8). These primers were used for comparative quantification of RUNX3 and TFF3 genes with qRT-PCR. 


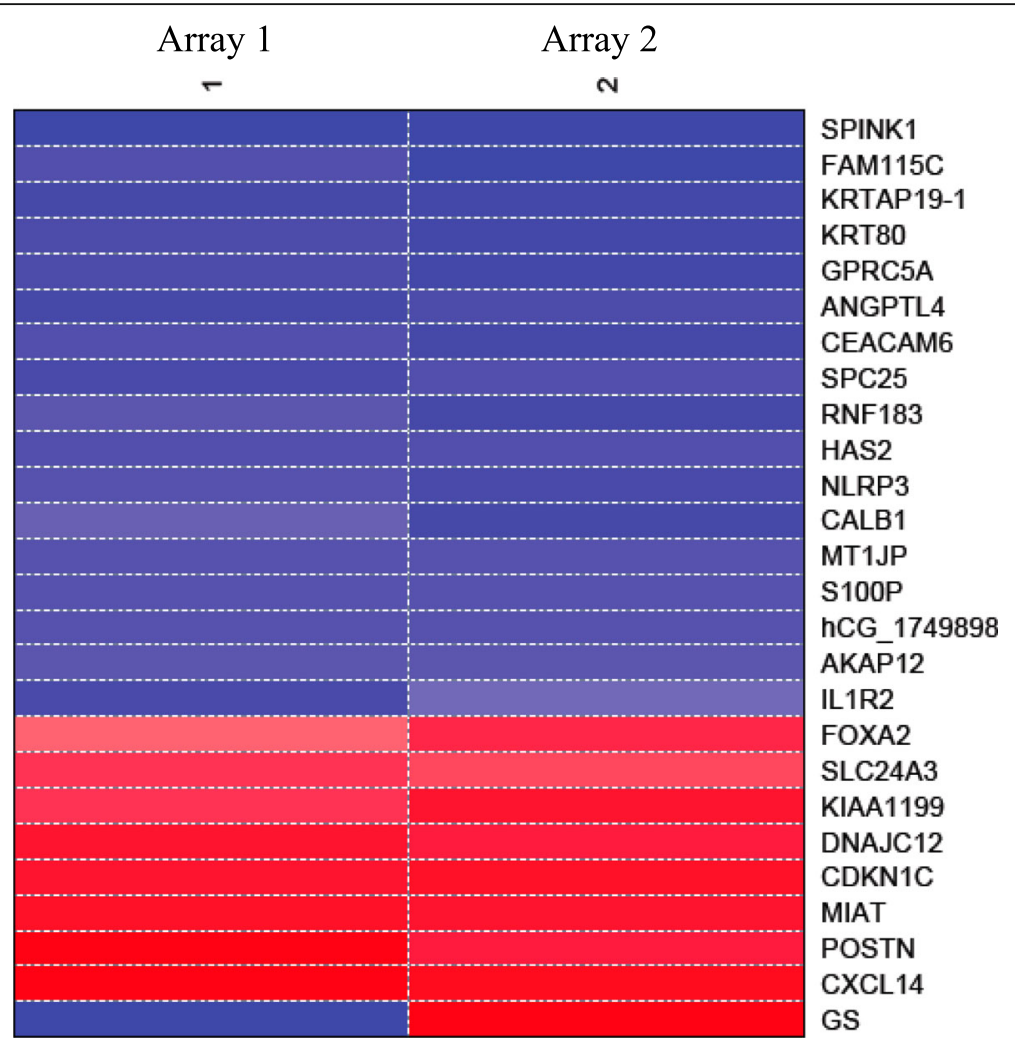

Fig. 2 Heat map of top 25 differentially expressed genes in PrEC-31 (+/-CD82) cells. GS: graphic scale for the array, where red represents downregulation and blue represents upregulation of a gene in the normal PrEC (+CD82) compared to siRNA treatment sample PrEC (-CD82). Columns 1, 2 represent the two arrays used i.e., array 1 and array 2 as a result of dye swapping

\section{qRT-PCR validation of microarray gene expression}

Gene expression data obtained from microarrays could be validated with qRT-PCR. RUNX3 has higher gene expression in CD82-restored PC3 clones (PC3-29 and PC3-57) (Fig. 5) compared with PC3-5 V -CD82 but was downregulated in normal prostate cells by PrEC$31+$ CD82 (Fig. 6), as observed from the microarray data. Student t-test comparing the final fold change difference of RUNX3 between cell lines yielded $p$ values of 0.12 (PC3-5 V vs PC3-29), 0.09 (PC3-5 V vs PC3-57) and 0.44 (PrEC-31; + vs - CD82) respectively. On the other hand, TFF3 showed higher gene expression in all + CD82 cells when compared with -CD82 cells (Figs. 7 and 8), correlated with the respective microarray data. The $\mathrm{p}$ values for TFF3 gene expression were 0.08 (PC3$5 \mathrm{~V}$ vs $\mathrm{PC} 3-29), 0.18$ (PC3-5 V vs $\mathrm{PC} 3-57)$ and 0.47 (PrEC-31; + vs - CD82) respectively.

\section{Discussion}

CD82 as tumor metastasis suppressor plays an important role in preventing primary tumor progression to a metastatic stage. Thus, CD82 is found downregulated in many metastatic human cancers. In metastatic prostate cancer cells, although c-Met signalling pathway has been identified to be regulated by CD82 (30), additional pathways may be involved. One way to further determine the genes and the pathways associated with CD82 is by identifying the differentially expressed genes in prostate cells with or without CD82. In this study, we used a whole human genome gene expression microarray to identify genes and subsequent pathways that are regulated by CD82 in normal and metastatic prostate cells (PrEC-31 and PC3).

Top 25 differentially expressed genes from the 3 microarray data sets: PrEC-31 (+CD82) vs. PrEC-31 (-CD82), PC3-57 (+CD82) vs. PC3-5 V (-CD82), and PC3-29 (+CD82) vs. PC3-5 V (-CD82) did not show overlapped results, except CALB1 which was upregulated in both PrEC-31 and PC3-29 CD82 expressed cells. CALB1 encodes calcium-binding protein calbindin 1 that is thought to play a role in apoptosis inhibition. However, CALB1 expression is reported to correlate with improved survival of patients with lung cancer [58], contradicting with reports that suggested an association of CALB1 upregulation with cancer stemness in meningiomas [59] and senescence inhibition in ovarian cancer [60]. The discrepancy may be due to different cell types and detection techniques that were used. Our study showed downregulation of CALB1 in CD82 negatively expressed normal and metastatic prostate cells 


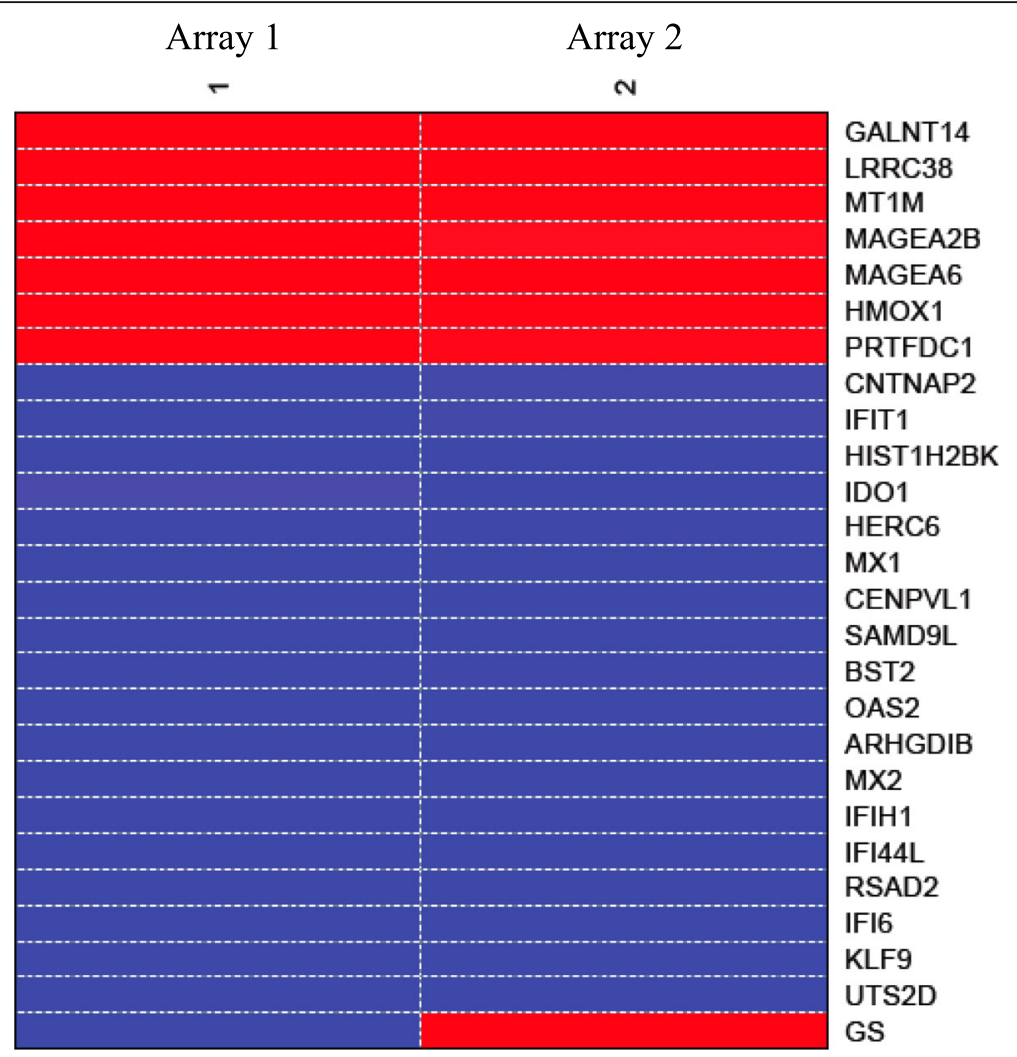

Fig. 3 Heat map of top 25 differentially expressed genes in PC3-57 vs. PC3-5 V cells. GS: graphic scale for the array, where red represents upregulation and blue represents downregulation of a gene in the treatment PC3-57 (+CD82) compared to control PC3-5 V (-CD82). Columns 1, 2 represent the two arrays used i.e., array 1 and array 2 as a result of dye swapping

(PrEC-31 and PC3). Low CD82 expression has been reported to correlate with increased invasiveness and decreased calcium-related cell-cell adhesion and adhesion to fibronectin in bladder cancer cell lines [61]. Although the relation between CALB1 and CD82 is currently unknown, CD82 may interact with CALB1 to disrupt calcium homeostasis. Low CD82 coupled with low CALB1 may cause insufficient calcium binding to calcium ions in normal cells and osteoclasts during metastasis. This may enhance tumor development and bone metastasis in prostate cancer (as PC3 cells are from bone metastasis), as observed in metastatic breast cancer [62].

In PrEC-31 (+CD82) vs. PrEC-31 (-CD82) cells, we showed SPINK1 as the most differentially upregulated gene. In prostate cancer, EGFR signaling pathway induces SPINK1 trypsin inhibitor to promote EMT [63] and overexpression of SPINK1 represents its aggressive form [64]. Although studies have shown positive association of SPINK1 expression with biochemical recurrence and castration-resistant prostate cancer [65], there was no significant difference in SPINK1 expression between incidental and metastatic cases [66]. The positive correlation between SPINK1 and CD82 expression in PrEC-31 normal prostate cells remains unexplained without further studies. CXCL14 was the most downregulated gene in PrEC-31 (+CD82) compared with PrEC-31 (-CD82). CXCL14 expression is known to upregulate in prostate cancer and positively correlate with its tumor progression [67, 68]. CXCL14, as a fibroblast autocrine growth factor can act as a prostate cancer stimulator [69] and high CXCL14 gene expression in -CD82 cells may indicate a possible link between CXCL14 and CD82 in the tumorigenesis of prostate cancer.

In one of the two PC3 metastatic prostate clonal cells (PC3-57) restored with CD82, we found GALNT14 as the most differentially upregulated gene when compared with CD82 negative cells. Aberrant glycosylation is a hallmark in various cancers and GALNT14, as a glycosyltransferase in the Golgi membrane, has been shown to promote lung-specific breast cancer metastasis by suppressing the bone morphogenetic protein signalling and activating the fibroblast growth factors to recruit macrophages for its metastatic microenvironment [70]. Here, we showed upregulation of GALNT14 in CD82 restored metastatic prostate cells and it is uncertain whether adding CD82 caused methylation that increased GALNT14 expression in those cells, as seen in many cancers [71] or is due to some other mechanism. UTS2D 


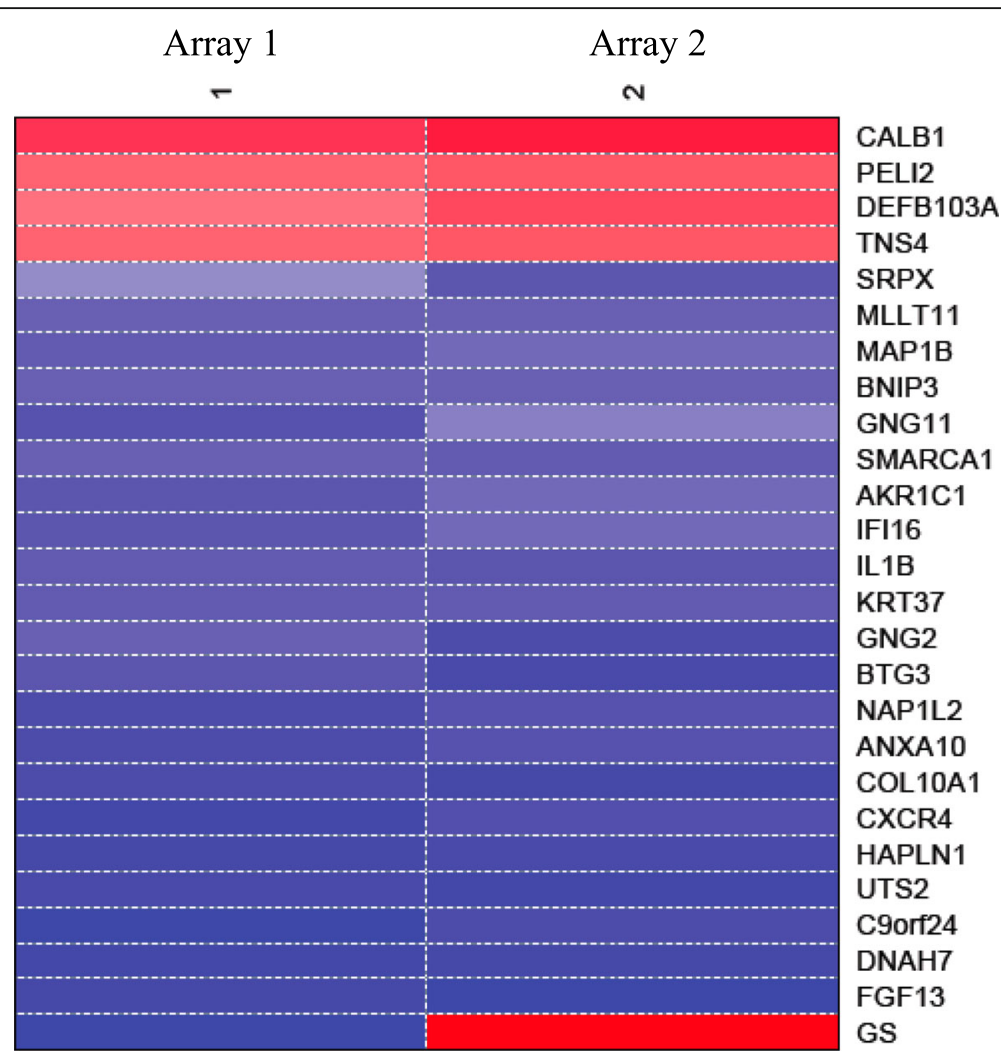

Fig. 4 Heat map of top 25 differentially expressed genes in PC3-29 vs. PC3-5 V cells. GS: graphic scale for the array, where red represents upregulation and blue represents downregulation of a gene in the treatment PC3-29 (+CD82) compared to control PC3-5 V (-CD82). Columns 1, 2 represent the two arrays used i.e., array 1 and array 2 as a result of dye swapping

and FGF13 were the most downregulated genes in PC3$57(+\mathrm{CD} 82)$ and $\mathrm{PC} 3-29(+\mathrm{CD} 82)$ cells, respectively. UTS2D codes for urotensin 2 (UTS2), a vasoconstrictor that binds to urotensin 2 receptor (UTS2R) in the G protein coupled receptor (GPCR) pathway. In prostate cancer, two studies showed an association of lower UTS2R expression with higher Gleason score and a more advanced cancer stage [72, 73], while a recent study demonstrated the opposite results i.e., a higher UTS $2 R$ expression correlated with higher grade and cancer stage [74]. In PC3 cells that have lower CD82 expression (PC3-5 V -CD82), although we did not find significant changes in UTS2R, we detected significantly higher UTS2D gene expression when compared with the $+\mathrm{CD} 82$ cells. If CD82 is involved in UTS2D/UTS2R mediation, developing UTS $2 R$ blockers may be a potential treatment avenue for prostate cancer, as suggested by Zappavigna et al. [75]. Fibroblast growth factors (FGFs) are proteins that are involved in various important biological processes, including cell differentiation and migration. In prostate cancer, FGF13 could act as an onco-switch [76] and its expression was higher in malignant as well as locally invasive and metastatic cells when compared with benign control cells [77]. High expression of FGF13 regulated by E2F1 transcription factor was reported to correlate with a shorter cell migration time to metastatic sites in breast cancer [78]. Additionally, up-regulated FGF13 gene expression was identified in highly metastatic breast cancer cells [79]. High expression of FGF13 in metastatic prostate -CD82 cells observed in our study indicates a potential interaction between FGF13 and CD82 to promote metastasis in prostate cancer.

A possible explanation for the discrepant top 25 differentially expressed gene lists within the 3 data sets is that different type of prostate cells were used in this study. PrEC-31 is a normal prostate cell line isolated from a patient after prostatectomy, while PC3 is a metastatic prostate cell line isolated from bone; both cell lines were also cultured in different culture conditions. Additionally, PC3-5 V, PC3-57, and PC3-29 are clonal cell lines derived from PC3. Discrepant results between PC3-57+ CD82 and PC3-29+CD82 clonal cells when compared with PC3-5 V -CD82 cells may be due to the fact that prostate tumor can harbor multiple genetically distinct cancer clones with heterogenous ERG+, ETS+, SPI+ and triple negative subtypes $[80,81]$ that can affect different gene regulation and pathways. Moreover, high vs. low 
Table 5 Key pathways regulated by CD82 in prostate cancer cells from top 100 significant genes from all three data array sets

\begin{tabular}{|c|c|c|c|c|c|}
\hline $\begin{array}{l}\text { Gene } \\
\text { Name }\end{array}$ & Gene ID & Gene Description & $\begin{array}{l}\text { PC3-57 } \\
\text { Array } \\
\text { (logFC) }\end{array}$ & $\begin{array}{l}\text { PC3-29 } \\
\text { Array } \\
\text { (logFC) }\end{array}$ & $\begin{array}{l}\text { PrEC-31 } \\
\text { Array } \\
\text { (logFC) }\end{array}$ \\
\hline \multicolumn{6}{|c|}{ Cell proliferation and angiogenesis } \\
\hline ANXA3 & NM_002754.3 & Homo sapiens annexin A3 & +0.504 & +1.302 & +1.218 \\
\hline MAPK3 & NM_002754 & Homo sapiens mitogen-activated protein kinase 13 & +0.715 & +0.874 & +0.816 \\
\hline LXN & NM_020169 & Homo sapiens latexin & +2.255 & +1.220 & +1.323 \\
\hline RUNX3 & NM_001031680 & Homo sapiens runt-related transcription factor 3, transcript variant 1 & +2.539 & +1.446 & -1.140 \\
\hline PIK3CA & NM_006218.2 & Homo sapiens phosphoinositide-3-kinase, catalytic, alpha polypeptide & -0.648 & -0.903 & +0.523 \\
\hline CDKN1C & NM_000076 & Homo sapiens cyclin-dependent kinase inhibitor 1C (p57, Kip2) & -1.105 & -1.319 & -3.227 \\
\hline BST2 & NM_004335 & Homo sapiens bone marrow stromal cell antigen 2 & -4.338 & -1.592 & +0.926 \\
\hline \multicolumn{6}{|c|}{ Migration \& Invasion } \\
\hline TFF3 & NM_003226 & Homo sapiens trefoil factor 3 (intestinal) & +3.835 & +2.071 & +0.926 \\
\hline CXCL2 & NM_002089 & Homo sapiens chemokine (C-X-C motif) ligand 2 & -1.521 & -1.422 & +1.699 \\
\hline \multicolumn{6}{|c|}{ Cell Apoptosis } \\
\hline LCK & NM_005356 & $\begin{array}{l}\text { Homo sapiens lymphocyte-specific protein tyrosine kinase, } \\
\text { transcript variant } 2\end{array}$ & +1.377 & +0.930 & -0.777 \\
\hline STEAP1 & NM_012449 & Homo sapiens six transmembrane epithelial antigen of the prostate 1 & -1.498 & -1.912 & - \\
\hline \multicolumn{6}{|l|}{ Cell cycle } \\
\hline$R \cup N \times 3$ & NM_001031680 & Homo sapiens runt-related transcription factor 3, transcript variant 1 & +2.539 & +1.446 & -1.140 \\
\hline CDKNIC & NM_000076 & Homo sapiens cyclin-dependent kinase inhibitor 1C (p57, Kip2) & -1.105 & -1.319 & -3.227 \\
\hline LCK & NM_005356 & $\begin{array}{l}\text { Homo sapiens lymphocyte-specific protein tyrosine kinase, transcript } \\
\text { variant } 2\end{array}$ & +1.377 & +0.930 & -0.776 \\
\hline FGF13 & NM_004114.3 & Homo sapiens fibroblast growth factor 13 & -0.765 & -3.955 & - \\
\hline \multicolumn{6}{|c|}{ Signal transduction pathways } \\
\hline MAPK13 & NM_002754 & Homo sapiens mitogen-activated protein kinase 13 & +0.715 & +0.874 & +0.816 \\
\hline LCK & NM_005356 & $\begin{array}{l}\text { Homo sapiens lymphocyte-specific protein tyrosine kinase, transcript } \\
\text { variant } 2\end{array}$ & +1.377 & +0.930 & -0.777 \\
\hline PIK3CA & NM_006218.2 & Homo sapiens phosphoinositide-3-kinase, catalytic, alpha polypeptide & -0.648 & -0.903 & +0.523 \\
\hline CXCL2 & NM_002089 & Homo sapiens chemokine (C-X-C motif) ligand 2 & -1.521 & -1.422 & +1.699 \\
\hline FGF13 & NM_004114.3 & Homo sapiens fibroblast growth factor 13 & -0.765 & -3.955 & - \\
\hline WNT5A & NM_003392.3 & Homo sapiens wingless-type MMTV integration site family, member $5 \mathrm{~A}$ & -0.577 & -1.094 & +1.634 \\
\hline PPFIA4 & NM_015053 & $\begin{array}{l}\text { Homo sapiens protein tyrosine phosphatase, receptor type, f polypeptide } \\
\text { (PTPRF), interacting protein (liprin), alpha } 4\end{array}$ & -1.192 & -1.649 & +2.211 \\
\hline \multicolumn{6}{|c|}{ Metabolic pathways } \\
\hline TFF3 & NM_003226 & Homo sapiens trefoil factor 3 (intestinal) & +3.835 & +2.071 & +0.926 \\
\hline MMP23B & NM_006983 & Homo sapiens matrix metallopeptidase 23B & +0.987 & +0.889 & - \\
\hline
\end{tabular}

metastatic cells have been known to be derived from parental PC3 cells [82]. In addition, as RNA translation to proteins is regulated by many molecular aspects, higher or lower gene expression that we identified in our microarrays may not directly reflect their protein expression. However, pathway analysis using gene expression data may provide mechanistic insight into how CD82 functions in prostate cells. We selected top 100 differentially expressed genes that were mutually inclusive in all 3 data sets to perform pathway analysis. Key pathways related with cell proliferation and angiogenesis, migration and invasion, cell death, cell cycle, signal transduction, and metabolism were identified in prostate cells, regulated by CD82. In general, these pathways are associated with oncogenesis and metastasis.

We performed qRT-PCR on RUNX3 and TFF3, two genes that were consistently up regulated in all $+\mathrm{CD} 82$ cells (except RUNX3 which was downregulated in PrEC$31+\mathrm{CD} 82)$. Quantitative comparison of RUNX3 and TFF3 expression levels measured with qRT-PCR showed higher gene expression in all +CD82 cells except PrEC$31+\mathrm{CD} 82$, which was consistent with our microarray 


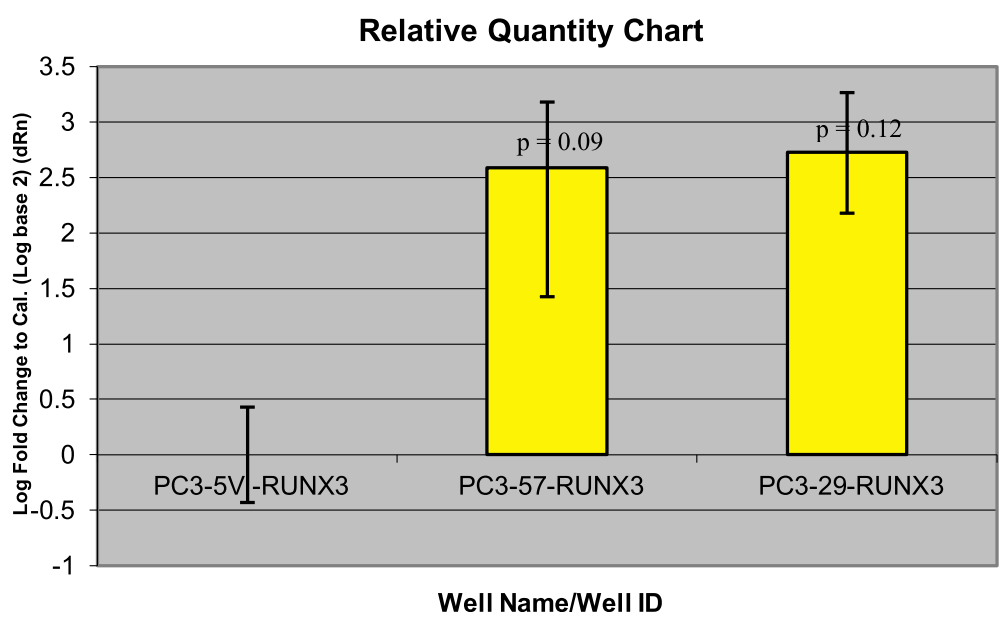

Fig. 5 Comparative quantification for RUNX3 gene in PC3 cell lines using qRT-PCR. PC3-5 V cell line was used as the calibrator. Yellow bars represent the log-fold change for the PC3-57 and PC3-29 cell lines compared to PC3-5 V. Fold change were initially calculated for all the three cell lines by subtracting RUNX3 Ct values from the respective cell lines beta actin Ct values. The fold change for PC3-5 V cell lines was equaled to 0 and the values for PC3-57 and PC3-29 were calculated by comparing to PC3-5 V. A t-test performed on the final fold change values yielded $p$ values of 0.12 (PC3-29) and 0.09 (PC3-57) respectively

results (Table 5). A t-test comparing the log fold changes in the expression of these genes did not show statistical significance.

$R U N X 3$, a runt-related transcription factor, is identified as a tumor suppressor gene in a wide variety of invasive and preinvasive epithelial and mesenchymal tumors [83]. RUNX3 is suggested to play a significant role in promoting apoptosis and inhibition of angiogenesis, EMT, cell migration, and invasion [84]. Its tumor suppressive activity was first identified in gastric epithelial cells of RUNX3 knockdown mice, where absence of
RUNX3 resulted in increased proliferative activity, suppressed apoptosis and decreased sensitivity to transforming growth factor beta (TGF- $\beta$ ) [85]. RUNX3 has since been identified as a downstream regulator of TGF- $\beta$ signaling pathway, by inducing CDKN1A (p21) gene expression in gastric cells [86] and upregulating the expression of proapoptotic gene BCL2L11 (Bim) in TGF- $\beta$ treated cells [87]. As a mediator of TGF- $\beta$ signaling, RUNX3 has been shown to inhibit EMT that promotes metastasis in gastric cancer [88] and hepatocellular carcinoma cells [89]. Additionally, re-expression of RUNX3

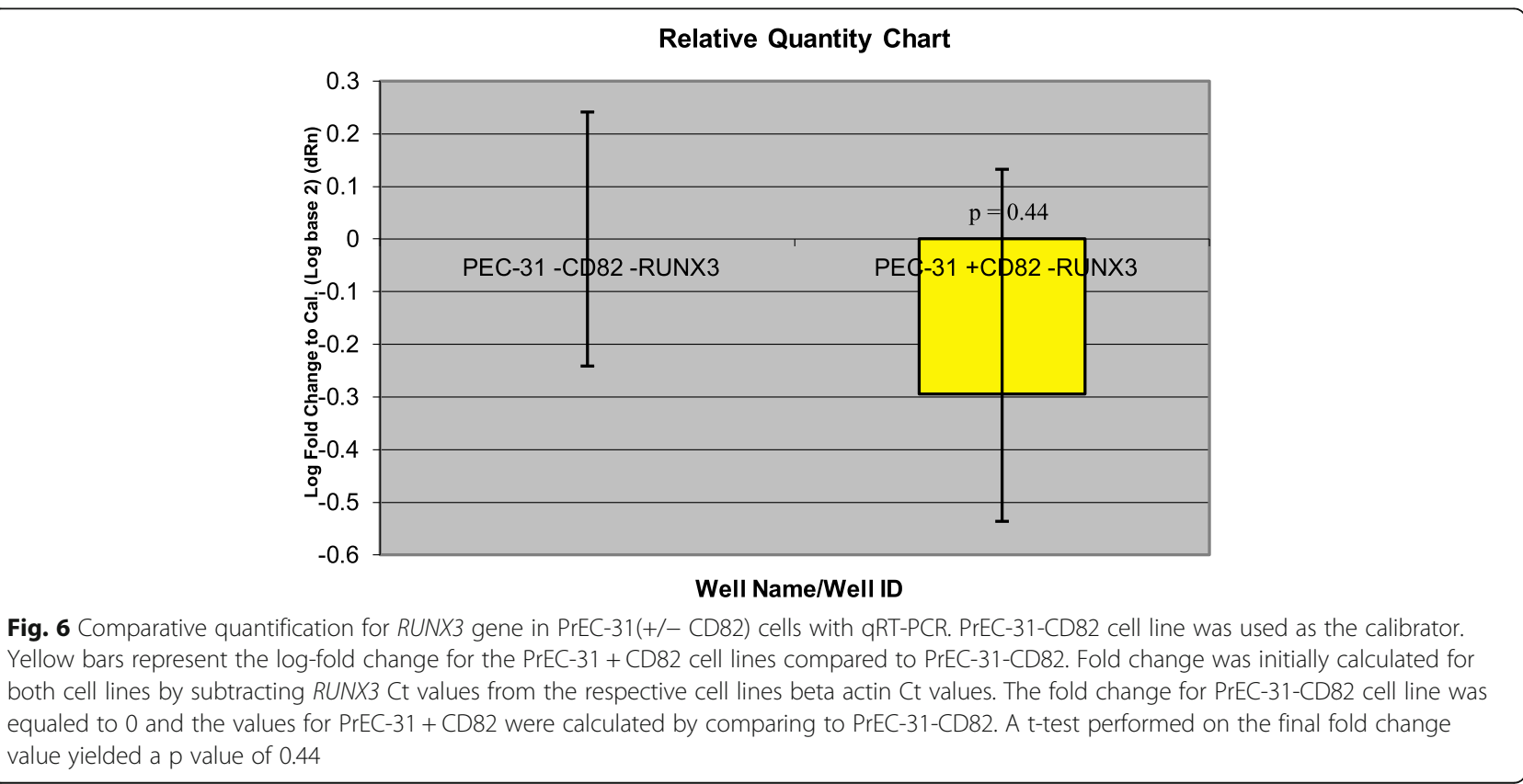




\section{Relative Quantity Chart}

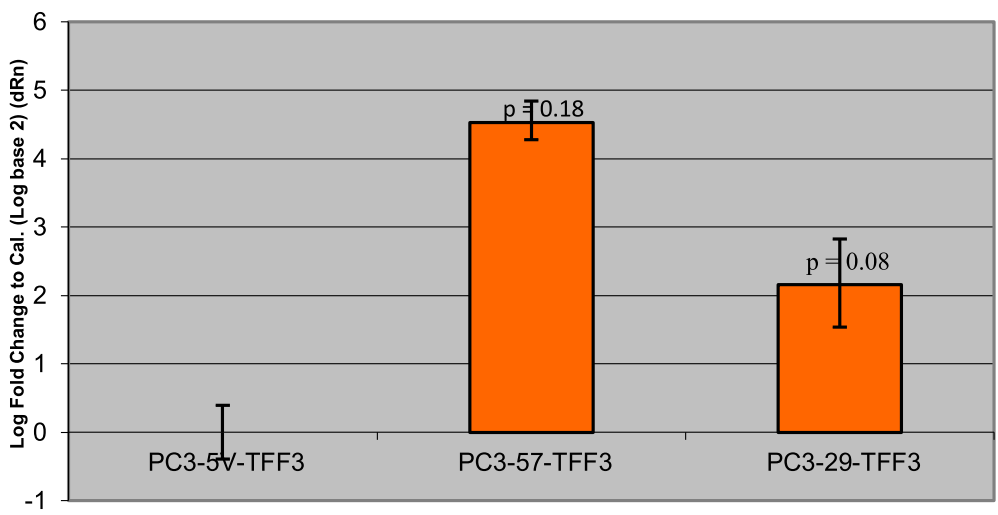

Well Name/Well ID

Fig. 7 Comparative quantification for TFF3 gene in PC3 cells using qRT-PCR. PC3-5V cell line was used as the calibrator. Yellow bars represent the log-fold change for the PC3-57 and PC3-29 cell lines compared to PC3-5 V. Fold change was initially calculated for all the three cell lines by subtracting TFF3 Ct values from the respective cell lines beta actin Ct values. The fold change for PC3-5 V cell line was equaled to 0 and the values for PC3-57 and PC3-29 were calculated by comparing to PC3-5 V. A t-test performed on the final fold change values yielded $p$ values of 0.08 (PC3-29) and 0.18 (PC3-57) respectively

in gastric cells in a mouse model inhibited peritoneal metastasis [90] and RUNX3 restoration in human gastric cancer cells suppressed vascular endothelial growth factor A (VEGF A) expression, leading to inhibition of angiogenesis, growth, and metastasis [91]. In prostate cancer, reduced levels of $R U N X 3$ have been correlated with tumor stage and grade [92]. RUNX3 overexpression in prostate cancer cells showed inhibition in cell migration and invasion with an upregulation of tissue inhibitor of matrix metalloproteinase-2 (TIMP-2). The functional role exhibited by RUNX3 is very similar to the role CD82 plays in prostate cells, i.e., CD82 reexpression has been shown to inhibit EMT (36), inhibit migration and invasion (30) and its down-regulation has been correlated with poor prognosis (2-4) in prostate cancer. $\mathrm{Al}$ though we are unclear of the association between CD82 and RUNX3 in our study, CD82 reexpression seems to promote upregulation of $R U N X 3$ in metastatic prostate cells.

On the other hand, TFF3 or trefoil factor 3 is a secretory protein that plays an important part in mucosal protection by promoting cell migration and preventing apoptosis [93]. TFF3 is secreted in various tissues, including pancreas, salivary glands, lacrimal glands,

\section{Relative Quantity Chart}

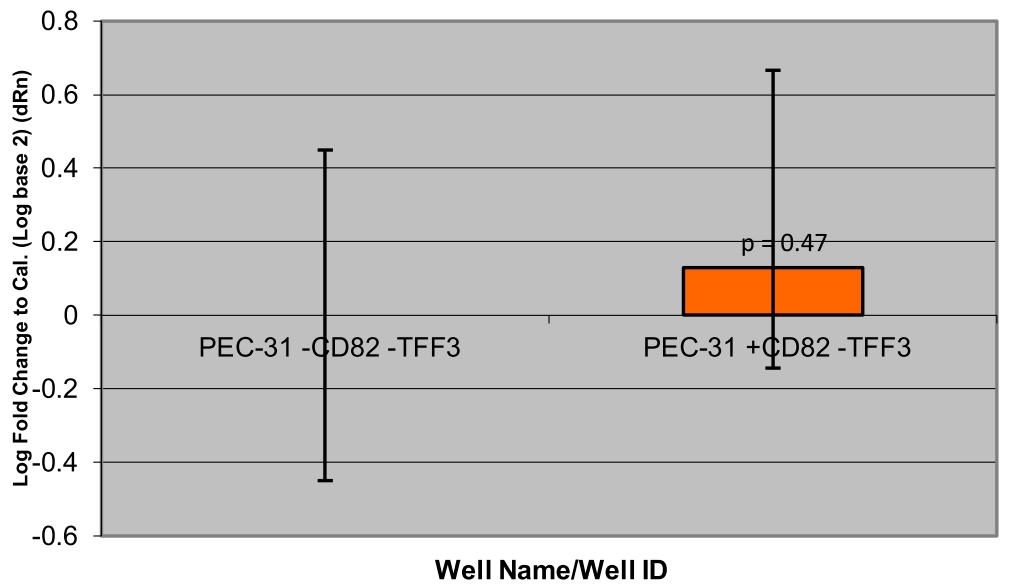

Fig. 8 Comparative quantification for TFF3 gene in PrEC-31(+/- CD82) cells using qRT-PCR. PEC-31-CD82 cell line was used as a calibrator. Yellow bars represent the log-fold change for the PEC-31 + CD82 cell lines compared to PEC-31-CD82. Fold change was initially calculated for both cell lines by subtracting TFF3 Ct values from the respective cell lines beta actin Ct values. The fold change for PEC-31-CD82 cell line was equaled to 0 and the values for PEC-31 + CD82 were calculated by comparing to PEC-31-CD82. A t-test performed on the final fold change yielded a $p$ value of 0.47 
prostate, breast, uterus, respiratory tract, and hypothalamus $[94,95]$. In prostate cancer, TFF3 expression was found to be up-regulated when compared to normal prostate tissue and TFF3 overexpression in PC3 cells was shown to increase proliferation, cell survival, and oncogenicity while reduce ionizing radiation sensitivity in prostate cells [96]. Our results showed increased TFF3 expression levels in all +CD82 cells and it correlated with the qRT-PCR data. .

\section{Conclusion}

In summary, even though earlier studies have explored the role of CD82 in prostate cancer and other cancer metastasis, our study was the first where we used microarray analysis to observe differential gene expression in prostate cells with and without CD82. We have identified multiple gene targets that could further be explored, including their association with CD82 in regulating prostate cancer metastasis. The significantly upregulated genes in -CD82 cells such as CXCL14 and FGF13 could potentially serve as biomarkers or therapeutic targets for diagnosis and treatment of prostate cancer.

\section{Supplementary Information}

The online version contains supplementary material available at https://doi. org/10.1186/s12885-020-07675-7.

Additional file 1.

Additional file 2.

\section{Abbreviations}

PrEC-31 cells: Human normal prostate cells derived from prostectomy (express CD82); PC3 cells: Human prostate cells derived from bone metastasis (do not express CD82); PC3-5 V: Vector transfected PC3 cells (do not express CD82); PC3-29 \& PC3-57: Stable clones of PC3 transfected with CD82 (express CD82); KAl1: Kangai 1 gene; CALB1: The calcium binding protein calbindin 1; SPINK1: Serine peptidase inhibitor kazal type 1; GALN T14: Polypeptide N-acetyl galactosaminyl transferase 14; CXCL14: C-X-C motif chemokine ligand 14; UTS2D: Urotensin 2; FGF13: Fibroblast growth factor 13; RUNX3: Runt-related transcription factor 3; TFF3: Trefoil factor 3;

EMT: Epithelial to mesenchymal transition

\section{Acknowledgments}

We would like to thank Dr. Beatrice Knundsen, University of Utah for her generous donation of the normal prostate epithelial cell lines (PrEC-31). We would also like to thank Dr. Kyle Furge and the Microarray core facility at VanAndel Research Institute, Grand Rapids, Ml for their help with the microarrays.

\section{Authors' contributions}

All authors have read and approved the manuscript. PD did majority of the work in this manuscript as part of her master's thesis work and also contributed to the corrections in the paper. VB contributed to one of the microarray data set as part of her master's thesis and also contributed to the corrections in the paper. SKK designed and conducted the microarray part of the study and contributed to the microarray analysis. She also contributed to a substantial amount of correction in the paper. CKM provided the cell lines used in the study. PC3 clones expressing CD82 were generated at her lab. She also contributed to the corrections in the paper. SS was the principal investigator for the project and contributed to the overall design, execution and funding for the project. She was the main author of the manuscript and also contributed to the corrections and formatting and is the corresponding author for the paper.

\section{Funding}

Funding for this study came from the Grand Valley State University Graduate School Presidential Research Grant awards for Pushpaja Dodla and Vanitha Bhoopalan, University Innovation Grant from West Michigan Science and Technology Initiative (WMSTI), Grand Valley State University Center for Scholarly and Creative Excellence Catalyst Grant, and University of South Florida Start-up Grant for Suganthi Sridhar.

- Graduate School Presidential Grant Award was used for microarray assays, collection and analysis of microarray data.

- University Innovation Grant from WMSTI was used for microarray and qRTPCR assays, cell cultures and western blots, collection and analysis of both microarray and GRT-PCR data.

- USF start-up grant was used for data analysis, data interpretation, manuscript writing and will be used to cover manuscript publication charges.

\section{Availability of data and materials}

All data generated or analysed during this study are included in this published article [and its supplementary information files].

Ethics approval and consent to participate

Not applicable.

\section{Consent for publication}

Not applicable.

\section{Competing interests}

The authors declare that they have no competing interests.

\section{Author details}

'Department of Cell and Molecular Biology, Grand Valley State University, Allendale, MI 49401, USA. ${ }^{2}$ Department of Cellular and Molecular Medicine, University of Arizona Cancer Center, University of Arizona, Tucson, AZ 85724, USA. ${ }^{3}$ Department of Integrative Biology, University of South Florida, 140, 7Th Avenue S, University of South Florida, St. Petersburg, FL 33701, USA.

Received: 28 July 2020 Accepted: 22 November 2020

Published online: 09 December 2020

\section{References}

1. Dong JT, Lamb PW, Rinker-Schaeffer CW, Vukanovic J, Ichikawa T, Isaacs JT, et al. KAl1, a metastasis suppressor gene for prostate cancer on human chromosome 11p11.2. Science. 1995;268:884-6.

2. Bouras T, Frauman AG. Expression of the prostate cancer metastasis suppressor gene KAl1 in primary prostate cancers: a biphasic relationship with tumour grade. J Pathol. 1999;188:382-8.

3. Tricoli JV, Schoenfeldt M, Conley BA. Detection of prostate cancer and predicting progression: current and future diagnostic markers. Clin Cancer Res. 2004;10:3943-53.

4. Ueda T, Ichikawa T, Tamaru J, Mikata A, Akakura K, Akimoto S, et al. Expression of the KAl1 protein in benign prostatic hyperplasia and prostate cancer. Am J Pathol. 1996;149:1435-40.

5. Hinoda Y, Adachi Y, Takaoka A, Mitsuchi H, Satoh Y, Itoh F, et al. Decreased expression of the metastasis suppressor gene KAl1 in gastric cancer. Cancer Lett. 1998;129:229-34.

6. Lombardi DP, Geradts J, Foley JF, Chiao C, Lamb PW, Barrett JC. Loss of KAl1expression in the progression of colorectal cancer. Cancer Res. 1999;59: 5724-31.

7. Takaoka A, Hinoda Y, Satoh S, Adachi Y, Itoh F, Adachi M, et al. Suppression of invasive properties of colon cancer cells by a metastasis suppressor KAl1 gene. Oncogene. 1998;16:1443-53.

8. Liu FS, Chen JT, Dong JT, Hsieh YT, Lin AJ, Ho ES, et al. KAl1 metastasis suppressor gene is frequently down-regulated in cervical carcinoma. Am J Pathol. 2001;159:1629-34.

9. Schindl M, Birner P, Bachtiary B, Breitenecker G, Selzer E, Oberhuber G. KAl1 metastasis suppressor protein in cervical cancer. Am J Pathol. 2002;160: $1542-3$.

10. Yang X, Wei L, Tang C, Slack R, Montgomery E, Lippman M. KAl1 protein is down-regulated. During the progression of human breast cancer. Clin Cancer Res. 2002;6:3424-9.

11. Yang X, Welch DR, Phillips KK, Weissman BE, Wei LL. KAl1, a putative marker for metastatic potential in human breast cancer. Cancer Lett. 1997;119:149-55. 
12. Geradts J, Maynard R, Birrer MJ, Hendricks D, Abbondanzo AL, Fong KM, et al. Frequent loss of KAl1 expression in squamous and lymphoid neoplasms. An immuno-histochemical study of archival tissues. Am J Pathol. 1999;154:1665-71.

13. Jackson P, Kingsley EA, Russell PJ. Inverse correlation between KAl1 mRNA levels and invasive behaviour in bladder cancer cell lines. Cancer Lett. 2000; 156:9-17.

14. Ow K, Delprado W, Fisher R, Barrett J, Yu Y, Jackson P, et al. Relationship between expression of the KAl1 metastasis suppressor and other markers of advanced bladder cancer. J Pathol. 2000;191:39-47.

15. Yu Y, Yang JL, Markovic B, Jackson P, Yardley G, Barrett J, et al. Loss of KAl1 messenger RNA expression in both high-grade and invasive human bladder cancers. Clin Cancer Res. 1997;3:1045-9.

16. Adachi M, Taki T, leki Y, Huang CL, Higashiyama M, Miyake M. Correlation of KAl1/CD82 gene expression with good prognosis in patients with non-small cell lung cancer. Cancer Res. 1996:56:1751-5.

17. Friess H, Guo XZ, Tempia-Caliera A, Fukuda A, Martignoni ME, Zimmermann $A$, et al. Differential expression of metastasis-associated genes in papilla of vater and pancreatic cancer correlates with disease stage. J Clin Oncol. 2001;19:2422-32.

18. Guo XZ, Friess H, Di Mola FF, Heinicke JM, Abou-Shady M, Graber H, et al. KAl1, a new metastasis suppressor gene, is reduced in metastatic hepatocellular carcinoma. Hepatology. 1998;28:1481-8.

19. Sun HC, Tang ZY, Zhou G, Li XM. KAl1gene expression in hepatocellular carcinoma and its relationship with intrahepatic metastases. J Exp Clin Cancer Res. 1998;17:307-11.

20. Chen Z, Mustafa T, Trojanowicz B, Brauckhoff M, Gimm O, Schmutzler C, et al. CD82 and CD63 in thyroid cancer. Int J Mol Med. 2004;14:517-27.

21. Zoller M. Tetraspanins: push and pull in suppressing and promoting metastasis. Nat Rev Cancer. 2009;9:40-55.

22. Maecker HT, Todd SC, Levy S. The tetraspanin superfamily: molecular facilitators. FASEB J. 1997;11:428-42.

23. Stipp CS, Kolesnikova TV, Hemler ME. Functional domains in tetraspanin proteins. Trends Biochem Sci. 2003:28:106-12.

24. Hemler M. Tetraspanin functions and associated microdomains. Nat Rev Mol Cell Biol. 2005;10:801-11

25. Miranti CK. Controlling cell surface dynamics and signaling: how CD82/ KAl1suppresses metastasis. Cell Signal. 2009;21:196-211.

26. Lee HA, Park I, Byun HJ, Jeoung D, Kim YM, Lee H. Metastasis suppressor KAl1/CD82 attenuates the matrix adhesion of human prostate cancer cells by suppressing Fibronectin expression and $\beta 1$ integrin activation. Cell Physiol Biochem. 2011;27:575-86.

27. Liu WM, Zhang XA. Kai1/cd82, a tumor metastasis suppressor. Cancer Lett. 2006;240:183-94.

28. Miranti C, Van Spriel AB, Bergsma A. Tetraspanins as master organizers of the plasma membrane. In: Cambi A, Lidke DS, editors. Cell membrane nanodomains: from biochemistry to nanoscopy. Boca Raton: CRC Press; 2014. p. 59-80.

29. Odintsova E, Sugira T, Berditchevski F. Attenuation of EGF rececptor signaling by a metastasis suppressor, the tetraspanin CD82/KAI 1. Curr Biol. 2000;10(16):1009-12

30. Sridhar S, Miranti CK. Tetraspanin KAI1/CD82 suppresses invasion by inhibiting integrin -dependent crosstalk with c-met receptor and Src kinases. Oncogene. 2006;25:2367-78.

31. Zhu J, Liang C, Hua Y, Miao C, Zhang J, Xu A, et al. The metastasis suppressor CD82/KAl1 regulates cell migration and invasion via inhibiting TGF- $\beta$ 1/Smad signaling in renal cell carcinoma. Oncotarget. 2017:8(31):51559-68.

32. Odintsova E, Voortman J, Gilbert E, Berditchevski F. Tetraspanin CD82 regulates compartmentalisation and ligand-induced dimerization of EGFR. J Cell Sci. 2003;116(Pt 22):4557-66.

33. Odintsova E, Van Niel G, Conjeaud H, et al. Metastasis suppressor Tetraspanin CD82/KAl1 regulates Ubiquitylation of epidermal growth factor receptor. J Biol Chem. 2013;288(36):26323-34.

34. Wang $X Q$, Yan $Q$, Sun $P$, et al. Suppression of epidermal growth factor receptor signaling by protein kinase C-alpha activation requires CD82, Caveolin-1, and Ganglioside. Cancer Res. 2007;67(20):9986-95.

35. Zhang XA, He B, Zhou B, Liu L. Requirement of the p130 CAS-Crk coupling for metastasis suppressor KAl1/CD82- mediated inhibition of cell migration. J Biol Chem. 2003;278(29):27319-28.

36. Lee J, Byun HJ, Lee MS, Jin YJ, Jeoung D, Kim YM, et al. The metastasis suppressor CD82/KAl1 inhibits fibronectin adhesion-induced epithelial-to- mesenchymal transition in prostate cancer cells by repressing the associated integrin signaling. Oncotarget. 2017;8(1):1641-54.

37. Abe M, Sugiura M, Takahashi T, et al. A novel function of CD82/KAl1 on Ecadherin-mediated homophilic cellular adhesion of cancer cells. Cancer Lett. 2008;266(2):163-70.

38. Lagaudriere-Gesbert C, Lebel-Binay S, Hubeau C, Fradelizi D, Conjeaud H. Signaling through the tetraspanin CD82 triggers its association with the cytoskeleton leading to sustained morphological changes and T cell activation. Eur J Immunol. 1998;28:4332-44.

39. Delaguillaumie A, Lagaudriere-Gesbert C, Popoff MR, Conjeud H. RhoGTPases link cytoskeletal rearrangments and activation processes induced via the tetraspanin CD82 in T lymphocytes. J Cell Sci. 2002;115(pt 2):433-43.

40. Delaguillaumie A, Harriague J, Kohanna S, Bismuth G, Rubinstein E, Seigneuret $M$, et al. Tetraspanin CD82 controls the association of cholesterol-dependent microdomains with the actin cytoskeleton in T lymphocytes: relevance to co-stimulation. J Cell Sci. 2004;117:5269-82.

41. Miranti CK, Park E. Regulation of E-cadherin and cell-cell adhesion by the metastasis suppressor tetraspanin KAl1/CD82. Clin Exp Metastasis. 2011; 28(2):176-7.

42. Larochelle J, Gillette M, Desmond R, Ichwan B, Cantilena A, Cerf A, et al. Bone marrow homing and engraftment of human hematopoietic stem and progenitor cells is mediated by a polarized membrane domain. Blood. 2012; 119(8):1848-55

43. Hur J, Choi Jl, Lee H, Nham P, Kim TW, Chae CW, et al. CD82/KAl1 maintains the dormancy of long-term hematopoietic stem cells through interaction with DARC-expressing macrophages. Stem Cells. 2016;18(4):508-21.

44. Bergsma A, Gangulya SS, Dick D, Williams BO, Miranti CK. Global deletion of tetraspanin CD82 attenuates bone growth and enhances bone marrow adipogenesis. Bone. 2018;113:105-13.

45. Bergsma A, Gangulya SS, Wiegand ME, Dick D, Williams BO, Miranti CK. Regulation of cytoskeleton and adhesion signaling in osteoclasts by tetraspanin CD82. Bone Reports. 2019;100196:1-11.

46. Uchtmann K, Park E, Bergsma A, Segula J, Edick MJ, Miranti CK. Homozygous loss of mouse tetraspanin CD82 enhances integrin allb $\beta 3$ expression and clot retraction in platelets. Exp Cell Res. 2015;339:261-9.

47. Vasmatzis GM, Essand U, Brinkmann B, Lee I, Pastan. Discovery of three genes specifically expressed in human prostate by expressed sequence tag database analysis. PNAS. 1998;95(1):300.

48. Zhang LW, Zhou VE, Velculescu SE, Kern RH, Hruban SR, Hamilton B, et al. Gene expression profiles in normal and cancer cells. Science. 1997;276(5316):1268.

49. Liang $P$, Pardee $A$. AB differential display of eukaryotic messenger RNA by means of the polymerase chain reaction. Science. 1992;257(5072):967.

50. Xu J, Stolk JA, Zhang X, Silva SJ, Houghton RL, Matsumura M, et al. Identification of differentially expressed genes in human prostate cancer using subtraction and microarray. Cancer Res. 2000;60(6):1677-82.

51. Rockett JC, Hellmann GM. Confirming microarray data--is it really necessary? Genomics. 2004:83(4):541-9.

52. Ginzinger DG. Gene quantification using real-time quantitative PCR: an emerging technology hits the mainstream. Exp Hematol. 2002;30(6):503-12.

53. Gmyrek GA, Walburg M, Webb CP, Yu HM, You X, Vaughan ED, et al. Normal and malignant prostate epithelial cells differ in their response to hepatocyte growth factor/scatter factor. Am J Pathol. 2001;159(2):579-90.

54. Bardwell L, Shah K. Analysis of mitogen-activated protein kinase activation and interactions with regulators and substrates. Methods. 2006;40(3):213-23.

55. Chomczynski P, Mackey K. Short technical report. Modification of the TRIZOL reagent procedure for isolation of RNA from polysaccharide-and proteoglycan-rich sources. Biotechniques. 1995;19(6):942-5.

56. Hosack DA, Dennis G Jr, Sherman BT, Lane HC, Lempicki RA. Identifying biological themes within lists of genes with EASE. Genome Biol. 2003;4(10):R70.

57. Morey JS, Ryan JC, Van Dolah FM. Microarray validation: factors influencing correlation between oligonucleotide microarrays and real-time PCR. Biol Proced Online. 2006;8(1):175-93.

58. Castro CY, Stephenson M, Gondo MM, Medeiros LJ, Cagle PT, et al. Prognostic implications of calbindin-D 28k expression in lung cancer: analysis of 452 cases. Mod Pathol. 2000;13(7):8-13.

59. Khan I, Baeesa S, Bangash M, Schulten HJ, Alghamadi F, Qashqari H, et al. Pleomorphism and drug resistant cancer stem cells are characteristic of aggressive primary meningioma cell lines. Cancer Cell Int. 2017;17:72-86.

60. Cao LQ, Wang YN, Liang M, Pan MZ. CALB1 enhances the interaction between p53 and MDM2, and inhibits the senescence of ovarian cancer cells. Mol Med Rep. 2019;9(6):5097-104. 
61. Jackson P, Kingsley EA, Russell PJ. Inverse correlation between KAl1 mRNA levels and invasive behaviour in bladder cancer cell lines. Cancer Lett. 2000; 156(1):9-17.

62. Yang Z, Yue Z, Ma X, Xu Z. Calcium homeostasis: a potential vicious cycle of bone metastasis in breast cancers. Front Oncol. 2010;10:293-310.

63. Wang C, Wang L, So B, Lu N, Song J, Yang $X$, et al. Serine protease inhibitor Kazal type 1 promotes epithelial-mesenchymal transition through EGFR signaling pathway in prostate cancer. Prostate. 2014;74(7):689-701.

64. Ateeq B, Tomlins SA, Laxman B, Asangani IA, Cao Q, Cao X, et al. Therapeutic targeting of SPINK1-positive prostate cancer. Sci Transl Med. 2011;3(72):72-90.

65. Zhang $X$, Yin $X$, Shen $P$, Sun $G$, Yang $Y$, Liu $Y$, et al. The association between SPINK1 and clinical outcomes in patients with prostate cancer: a systematic review and meta-analysis. Onco Targets Ther. 2017;10:3123-30.

66. Koide H, Kimura T, Inaba H, Sato S, Iwatani K, Yorozu T, et al. Comparison of ERG and SPINK1 expression among incidental and metastatic prostate cancer in Japanese men. Prostate. 2019;79(1):3-8.

67. Schwarze S, Luo J, Isaacs WB, Jarrard JF. Modulation of CXCL14 (BRAK) expression in prostate cancer. Prostate. 2005;64(1):67-74.

68. Eiro N, Fennadez-Gomez J, Sacristan R, Fernandez-Garcia B, Lobo B, Gonzalez-Suarez J, et al. Stromal factors involved in human prostate cancer development, progression and castration resistance. J Cancer Res Clin Oncol. 2017;143(2):351-9.

69. Augsten M, Sjoberg E, Frings O, Vorrink S, Frijhoff J, Olsson E, et al. Cancerassociated fibroblasts expressing CXCL14 rely upon NOS1-derived nitric oxide signaling for their tumor-supporting properties. Cancer Res. 2014; 74(11):2999-3010.

70. Song KH, Park MS, Nandu TS, Gadad S, Kim SC, Kim MY, et al. GALNT14 promotes lung-specific breast cancer metastasis by modulating self-renewal and interaction with the lung microenvironment. Nat Commun. 2016;7: 13796-811.

71. Vojta A, Samarzija I, Bockor L, Zoldas V. Glyco-genes change expression in cancer through aberrant methylation. Biochim Biophys Acta. 2016;1860(8): 1776-85.

72. Grieco P, Franco R, Bozzuto G, Toccacieli L, Sgambato A, Marra M, et al. Urotensin II receptor predicts the clinical outcome of prostate cancer patients and is involved in the regulation of motility of prostate adenocarcinoma cells. J Cell Biochem. 2011;112(1):341-53.

73. De Cobelli O, Buonerba C, Terracciano D, Boterro D, Lucarelli G, Bove P, et al. Urotensin II receptor on preoperative biopsy is associated with upstaging and upgrading in prostate cancer. Future Oncol. 2015;11(22): 3091-8.

74. Giulianelli R, Nardoni S, Bruzzese D, Falavolti C, Mirabile G, Bellangino M, et al. Urotensin II receptor expression in prostate cancer patients: a new possible marker. Prostate. 2019;79(3):288-94.

75. Zappavigna S, Abate M, Cossu AM, Lusa S, Campani V, Scotti L, et al. Urotensin-II-targeted liposomes as a new drug delivery system towards prostate and colon cancer cells. J Oncol. 2019;2019:1-14.

76. Tong $Y$, Song $Y$, Deng S. Combined analysis and validation for DNA methylation and gene expression profiles associated with prostate cancer. Cancer Cell Int. 2019;19:19-50.

77. Yu L, Toriseva M, Tuomala M, Seikkula H, Elo T, Tuomela J, et al. Increased expression of fibroblast growth factor 13 in prostate cancer is associated with shortened time to biochemical recurrence after radical prostatectomy. Int J Cancer. 2016;139(1):140-52.

78. Hollern DP, Swiatnicki MR, Rennhack JP, Misek SA, Matson BC, McAuliff A, et al. E2F1 drives breast Cancer metastasis by regulating the target gene FGF13 and altering cell migration. Sci Rep. 2019;9(1):10718-31.

79. Johnstone CN, Pattison AD, Harrison PF, Powell DR, Lock P, Ernst M, et al. FGF13 promotes metastasis of triple-negative breast cancer. Int J Cancer. 2020;147(1):230-43.

80. Smith SC, Tomlins SA. Prostate cancer SubtyPINg biomarkers and outcome: is clarity emERGing? Clin Cancer Res. 2014;20(18):4733-6.

81. Wang H, Li H, Mei Y, Huang X, Li Z, Yang Q, et al. Sp1 suppresses miR-3178 to promote theMetastasis invasion Cascade via Upregulation of TRIOBP. Mol Ther Nucleic Acids. 2018;12:1-11.

82. Ma H, Wang LY, Yang RH, Zhou Y, Zhou P, Kong L. Identification of reciprocal microRNA-mRNA pairs associated with metastatic potential disparities in human prostate cancer cells and signaling pathway analysis. J Cell Biochem. 2019;120(10):17779-90.
83. Subramaniam MM, Chan JY, Yeoh KG, Quek T, Ito K, Salto-Tellez M. Molecular pathology of RUNX3 in human carcinogenesis. Biochim Biophys Acta. 2009;1796:315-31.

84. Chen F, Liu X, Bai J, Pei D, Zheng J. The emerging role of RUNX3 in cancer metastasis. Oncol Rep. 2016;35:1227-36.

85. Li QL, Ito K, Sakakura C, Fukamachi H, Inoue K, Chi XZ, et al. Causal relationship between the loss of RUNX3 expression and gastric cancer. Cell. 2002;109:113-24.

86. Chi XZ, Yang JO, Lee KY, Ito K, Sakakura C, Li QL, et al. RUNX3 suppresses gastric epithelial cell growth by inducing p21(WAF1/Cip1) expression in cooperation with transforming growth factor-activated SMAD. Mol Cell Biol. 2005;25:8097-107.

87. Yano $T$, Ito $K$, Fukamachi $H$, Chi XZ, Wee HJ, Inoue $K$, et al. The RUNX3 tumor suppressor upregulates Bim in gastric epithelial cells undergoing transforming growth factor-induced apoptosis. Mol Cell Biol. 2006;26: 4474-88.

88. Voon DC, Wang H, Koo JK, Nguyen TA, Hor YT, Chu YS, et al. Runx3 protects gastric epithelial cells against epithelial-mesenchymal transition induced cellular plasticity and tumorigenicity. Stem Cells. 2012;30:2088-99.

89. Tanaka S, Shiraha H, Nakanishi Y, Nishina S, Matsubara M, Horiguchi S, et al. Runt-related transcription factor 3 reverses epithelial mesenchymal transition in hepatocellular carcinoma. Int J Cancer. 2012;131:2537-46.

90. Sakakura C, Hasegawa K, Miyagawa K, Nakashima S, Yoshikawa T, Kin S, et al. Possible involvement of RUNX3 silencing in the peritoneal metastases of gastric cancers. Clin Cancer Res. 2005;11:6479-88.

91. Peng Z, Wei D, Wang L, Tang H, Zhang J, Le X, et al. RUNX3 inhibits the expression of vascular endothelial growth factor and reduces the angiogenesis, growth, and metastasis of human gastric cancer. Clin Cancer Res. 2006;12:6386-94.

92. Chen F, Wang M, Bai J, Liu Q, Xi Y, Li W, et al. Role of RUNX3 in suppressing metastasis and angiogenesis of human prostate cancer. PLoS One. 2012;9: e86917.

93. Xiao P, Ling H, Lan G, Liu J, Hua H, Yang R. Trefoil factors. Gastrointestinalspecific proteins associated with gastric cancer. Clin Chim Acta. 2015;450: 127-34.

94. Xiao L, Liu YP, Xiao CX, Ren JL, Guleng B. Serum TFF3 may be a pharmacodynamic marker of responses to chemotherapy in gastrointestinal cancers. BMC Clin Pathol. 2012;14:1472.

95. Madsen IJ, Nielsen O, Tornoe T, Thim L, Holmskov U. Tissue localization of human trefoil factors 1, 2, and 3. J Histochem Cytochem. 2007:55:505-13.

96. Perera O, Evans A, Pertziger M, MacDonald C, Chen H, Liu DX, et al. Trefoil factor 3 (TFF3) enhances the oncogenic characteristics of prostate carcinoma cells and reduces sensitivity to ionising radiation. Cancer Lett. 2015:361:104-11.

\section{Publisher's Note}

Springer Nature remains neutral with regard to jurisdictional claims in published maps and institutional affiliations.

Ready to submit your research? Choose BMC and benefit from:

- fast, convenient online submission

- thorough peer review by experienced researchers in your field

- rapid publication on acceptance

- support for research data, including large and complex data types

- gold Open Access which fosters wider collaboration and increased citations

- maximum visibility for your research: over $100 \mathrm{M}$ website views per year

At $\mathrm{BMC}$, research is always in progress.

Learn more biomedcentral.com/submissions 